\title{
Cardiovascular Risk Assessment in Diabetes and Chronic Kidney Diseases: A New Insight and Emerging Strategies
}

\author{
Ali Reza Khoshdel \\ AJA University of Medical Sciences, Tehran,
}

Iran

\section{Introduction}

The post-millennium era witnesses a substantial epidemiologic transition in which cardiovascular disease (CVD) has taken more important role in mortality and morbidity in almost all parts of the world[1]. However, the natural history of CVD itself has also been evolving in parallel to changing life style and environmental risk factors. Nevertheless, despite a global movement for CVD control, the target points are still poorly achieved[2]. Therefore, a new look at the issue of CVD pathophysiology, CVD markers and risk assessment is necessary for a proper and effective care plan and targeting CVD prevention and control.

The classification of some elements to "risk factors" and "risk markers" has been controversial. There have been serious debates about the validity and impact of classic CVD risk factors. However, it is generally accepted that classic CVD risk factors cannot fully explain the epidemiology and natural history of the disease particularly in patients with co-morbidities. As a result several lists of emerging risk factors have been introduced with various clinical or research applications. Accordingly, several risk scores have been developed for risk assessment among various populations. Nevertheless, we face a network of associated risk factors with synergic effects, of which some factors play central roles and connect other factors together. For instance, central arterial pressure and arterial stiffness and also microalbuminuria have attracted more attention as summative CVD markers or risk factors and have been proposed as new targets for more efficient treatment.

Increasing evidence of cross-links among CVD, diabetes mellitus (DM) and chronic kidney disease (CKD) has been published in recent decades. DM and CKD are major comorbidities with CVD. In addition, several studies demonstrated greater frequency of CVD in DM and $\mathrm{CKD}$, even in very early stages. On the other hand, our recent research revealed a significant impact of minimal heart dysfunction on further development of renal impairment[3]. Then, it seems that CVD, CKD and DM shares many risk factors and influences each other in various stages. This could be demonstrated as a pyramid with facets of presentations and a common pathophysiologic base. Considering this network of associations, we have introduced the concept of circulatory (MARC) syndrome, which facilitates understanding, evaluation, detection and interventions on the CVD risk factors earlier, easier and more effective. This concept preserves the positive features of the so called "metabolic syndrome" 
but prevents its weaknesses and improves its clinical applications. This leads to a novel paradigm in CVD management with new checking points, new targets and better achievements in the patients' care.

\section{Epidemiologic trends in CVD risk factors}

CVD has been evolving through 4 epidemiologic transition periods[1] with increasing frequency of proportion of death due to CVD during the first 3 stages and a slight decrease in the disease rate in the $4^{\text {th }}$ stage, possibly due to controlling CV risk factors. However, it seems that a $5^{\text {th }}$ stage is being developed due to epidemic diabetes, hypertension, obesity and chronic kidney disease as well as leveling off the smoking session rate in combination to social and economic instability in many countries. Consequently, epidemiologic trends in CVD and CV risk factors have been changing during the past decades both in developed and in developing countries. Developing countries, in particular, experience a substantial rise in CVD and younger age at onset of the disease, which is partially attributed to their demographic remodeling including a high population growth rate and inverted population pyramid with a majority of young individuals [1]. Furthermore, these countries face to a "dual epidemiology" of contrasting an undernourished and poor population against a significant proportion of overweight and obese groups. The last World Health Organization report on global burden of disease and risk factors demonstrated that the highest rates of $\mathrm{CV}$ death were in Eastern Europe, Central Asia, Middle East and North Africa. Also six out of 10 countries with highest rate of diabetes were in Eastern Mediterranean and Middle East region. However, there was a considerable heterogeneity in other regions which reflects different stages of epidemiologic transitions even in a single country like China[1,4].

Eight risk factors (alcohol use, tobacco use, high blood pressure, high body mass index, high cholesterol, high blood glucose, low fruit and vegetable intake, and physical inactivity) account for $61 \%$ of cardiovascular deaths[4]. Moreover, air pollution, climate change, psychosocial stressors and maternal-foetal metabolic adaptation are also introduced as important CV risk factors[1]. However the pattern of the risk factors differs in subgroups of age, gender and patient groups while some factors loses their impact in parallel to homogeneity of the factor in the group[5]. It also evolves as a population passes through epidemiologic transitions from traditional to emerging risk factors.

From a practical perspective, primary and secondary prevention must be arranged for modifiable risk factors. The Framingham Study and subsequently the INTERHEART study have identified the important risk factors and targets for modification. Moreover, an analysis of 10 studies across the world in which there has been a decline in CVD mortality, demonstrated that risk factor modification was associated with $44 \%$ of the decline in the Netherlands, $50-54 \%$ in the USA, and $76 \%$ in North Karelia, Finland. New treatments are responsible for $23-47 \%$ of the decline in mortality[1]. Although, economic, cultural and logistic conditions have various impacts on preventive strategies in different population; risk assessment is a fundamental step for any CV preventive strategy.

\subsection{CV risk in diabetes mellitus}

CVD is the leading cause of mortality among DM patients [6,7] with the prevalence of, incidence of, and mortality from all forms of CVD being 2-8 fold higher in diabetics when 
compared to a non-diabetic population. DM is accompanied with various cardiovascular abnormalities including endothelial dysfunction, increased oxidative stress and micro- and macrovascular consequences leading to coronary artery disease, left ventricular dysfunction (particularly diastolic dysfunction), hypertensive heart disease and reduced cardiac reserve[8]. A different trend in CV risk factors has been reported in patients with and without DM in Framingham Study from 1970 to 2005. This study demonstrated a greater increase in BMI, greater decrease in cholesterol and similar reduction in hypertension in DM when compared to non-DM[2].

The special writing group for the American Heart Association established that the goal of risk assessment would be to identify subclinical CVD in patients with DM which would lead to better management and improvement in disease morbidity and mortality. Furthermore they also designated DM as a "coronary risk equivalent" and indicated that DM patients belong in the same risk category as patients with known CVD[9]. This risk increases with age (>35 yrs), younger age at onset of DM, duration of DM (>10 yrs), presence of microvascular complications and other CV risk factors [10,11]. Screening and CV risk assessment of DM patients is also strongly recommended in many guidelines including a French guideline which recommended screening for silent myocardial ischemia (including exercise stress testing) in DM patients with one additional risk factor [9]. However, the American Heart Association recommended exercise testing in this group when individuals plan moderate to high intensity exercise[11]. Furthermore, while the hemodynamic response to increased physical activity is a predictor of future hypertension [12] and is helpful in the early diagnosis of heart failure[13], it might also provide further information about the factors contributing to impaired cardiovascular control even in DM patients without additional risk. Accordingly, we demonstrated in a study of more than 17000 patients (including 1722 DM pts) an impaired hemodynamic response to exercise stress testing in DM group compared to non-diabetics and most importantly showed that the responses predicts the development of ESRD in diabetic patients[3, 14-16]. (Figure 1) Furthermore, in an outpatient setting of patients with diabetes and hypertension; we reported a substantial proportion of patients being non-dipper for nocturnal blood pressure. This study also showed an inverse relationship between white coat hypertension and arterial stiffness or microalbuminuria[17]. A comparison between normal individuals, patients with impaired fasting glucose, and diabetic patients did also demonstrate an increment of arterial stiffness in these groups[18]. In conclusion, all above evidence indicate subclinical arterial changes early in DM.

\subsection{CV risk in diabetic kidney disease}

About $10-40 \%$ of patients with diabetes mellitus (DM) develop nephropathy. Consequently with an increasing DM global prevalence and an aging population, DM has become the leading single cause of ESRD in many developed and developing countries [19-24]. Moreover, it is now proven that even a mild reduction in kidney function is accompanied by an increased cardiovascular (CV) risk [25, 26]. In addition, cardiac and renal DM complications share many risk factors and markers including microalbuminuria $(\mathrm{mA})$, atherosclerosis and arteriosclerosis [27-29]. Therefore, evaluation and treatment of renal risk factors should not only prevent progression to End-Stage Renal Disease (ESRD), but also reduce $\mathrm{CV}$ risk. 


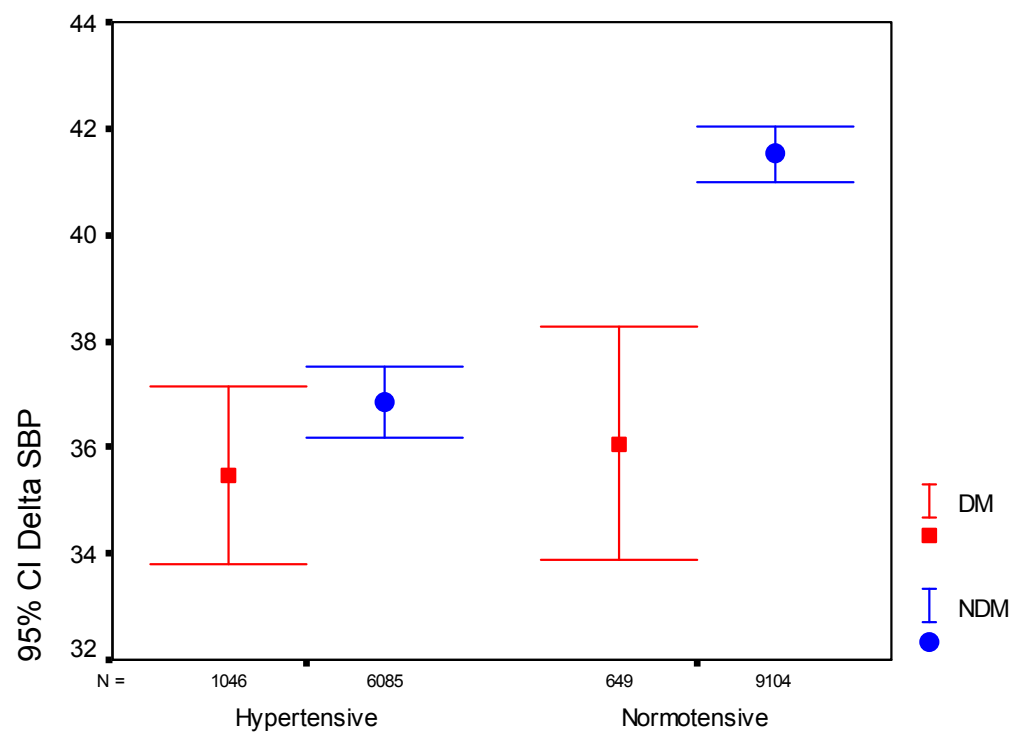

Groups

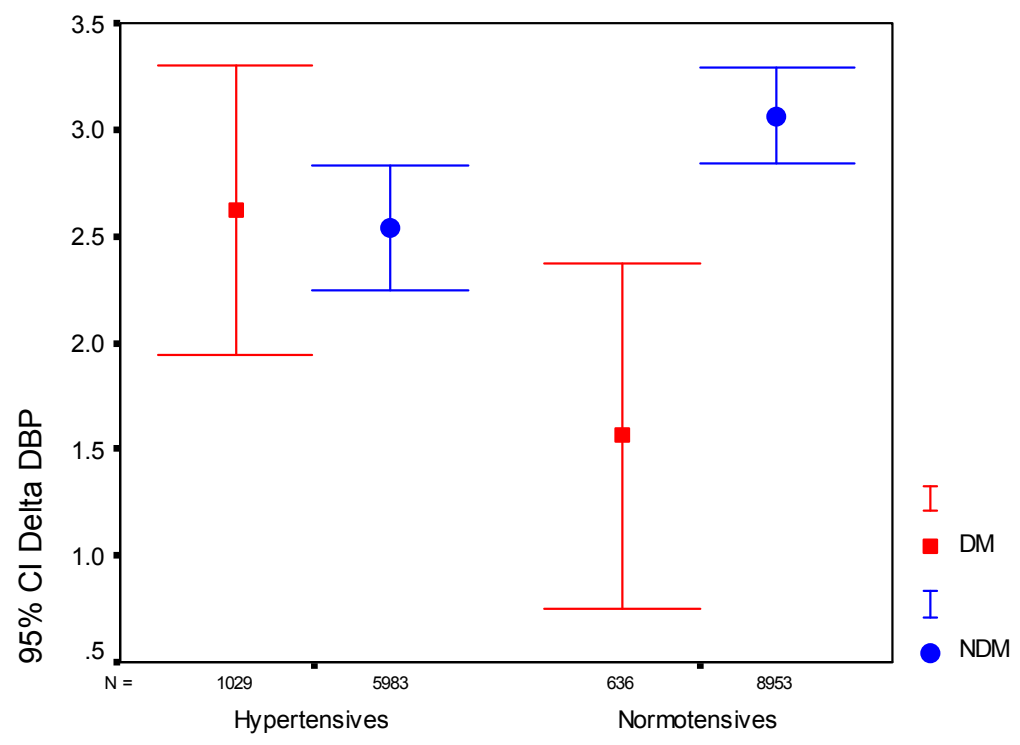

GROUPS

Fig. 1. Differential response of DM and NDM to the exercise test in hypertensive and normotensive subgroups 
While the development and progression of renal damage in DM occurs very slowly, it often remains subclinical and undiagnosed for years [30], which inhibits effective prevention and intervention at a time when renal damage may be reversible. Therefore, early identification of diabetic nephropathy ( $\mathrm{DN})$ is a medical priority [31,32]. Although $\mathrm{mA}$ is currently regarded as an early marker of $\mathrm{DN}$, it is now preferably considered as a marker of a generalized endotheliopathy and then a CV risk marker. However, irreversible damage has often occurred when $\mathrm{mA}$ is detected $[30,33]$. Furthermore, $\mathrm{mA}$ may not accurately represent the severity of renal damage, absent in marked renal dysfunction $[34,35]$ or may regress or fluctuate during the disease [34,36]. Consequently, other markers, preferably in their early stages, should also be investigated as a potential guide to the progression of ESRD [31]. Arterial compliance changes occur early in DM and since arterial stiffness is an established independent predictor of mortality in the later stages of nephropathy [37-39], it should also correlate with renal function and BP profile in the earlier stages of DM.

Based on the above understanding, we made a large study including several subsets with various range of kidney function and compared CV risk factors in DM and non-DM, focusing on early stages in particular. The findings indicated that even in early stages of renal impairment without clinical presentation, DM patients had a greater level of arterial stiffness compared to non-DM. As a result, indices of arterial stiffness could be applied for a better CV risk management particularly in DM[40]. (Figure2). Multivariant analysis revealed arterial stiffness, hemoglobin, systolic blood pressure and triglyceride as the main determinants of renal function in DM (Table 1). Application of artificial neural network for analysis of major predictors of kidney function also determined arterial stiffness, hemoglobin, triglyceride, diabetes and blood pressure profile among major determinants of renal function.

Central PWV Difference

between diabetic and non-diabetics

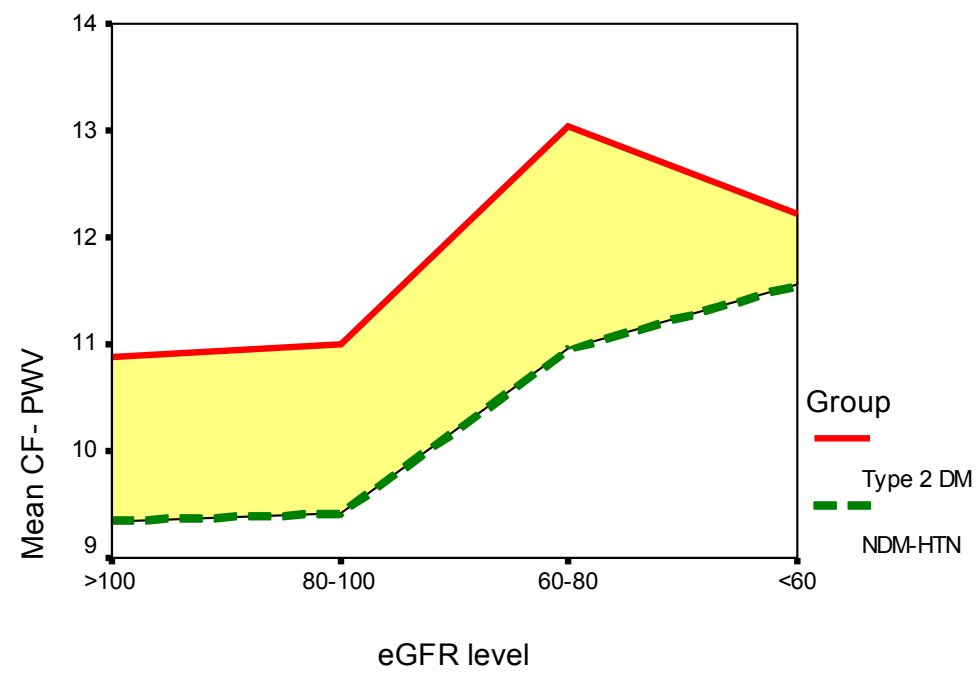

Fig. 2. Difference in the central arterial stiffness (as measured with CF-PWV) between type 2DM and NDM groups across levels of eGFR 


\begin{tabular}{|c|c|c|c|c|c|c|c|c|}
\hline Adj. $R^{2}$ & $\begin{array}{l}\text { Model } 1 \\
48 \%\end{array}$ & \begin{tabular}{|l|} 
Model 2 \\
$49 \%$
\end{tabular} & $\begin{array}{l}\text { Model } 3 \\
50 \%\end{array}$ & $\begin{array}{l}\text { Model } 4 \\
51 \%\end{array}$ & $\begin{array}{l}\text { Model } 5 \\
52 \%\end{array}$ & $\begin{array}{l}\text { Model } 6 \\
52 \%\end{array}$ & $\begin{array}{l}\text { Model } 7 \\
53 \%\end{array}$ & $\begin{array}{l}\text { Model } 8 \\
52 \%\end{array}$ \\
\hline $\mathbf{r T r}$ & $\begin{array}{l}0.397 \\
0.259\end{array}$ & $\begin{array}{l}0.403 \\
0.245\end{array}$ & $\begin{array}{l}0.393 \\
0.249\end{array}$ & $\begin{array}{l}0.411 \\
0.222\end{array}$ & $\begin{array}{l}0.410 \\
0.219\end{array}$ & $\begin{array}{l}0.202 \\
0.116\end{array}$ & $\begin{array}{l}0.202 \\
0.115\end{array}$ & $\begin{array}{l}0.298 \\
0.009\end{array}$ \\
\hline $\begin{array}{l}\text { Male } \\
\text { Gender }\end{array}$ & $\begin{array}{l}-0.279 \\
0.038\end{array}$ & $\begin{array}{l}-0.278 \\
0.036\end{array}$ & $\begin{array}{l}-0.263 \\
0.033\end{array}$ & $\begin{array}{l}-0.282 \\
0.015\end{array}$ & $\begin{array}{l}-0.288 \\
0.012\end{array}$ & $\begin{array}{l}-0.275 \\
0.014\end{array}$ & $\begin{array}{l}-0.269 \\
0.015\end{array}$ & $\begin{array}{l}-0.281 \\
0.012\end{array}$ \\
\hline $\begin{array}{l}\text { CV } \\
\text { disease }\end{array}$ & $\begin{array}{l}-0.273 \\
0.040\end{array}$ & $\begin{array}{l}-0.275 \\
0.037\end{array}$ & $\begin{array}{l}-0.269 \\
0.037\end{array}$ & $\begin{array}{l}-0.287 \\
0.018\end{array}$ & $\begin{array}{l}-0.280 \\
0.020\end{array}$ & $\begin{array}{l}-0.283 \\
0.018\end{array}$ & $\begin{array}{l}-0.282 \\
0.017\end{array}$ & $\begin{array}{l}-0.277 \\
0.021\end{array}$ \\
\hline $\mathrm{Hb}$ & $\begin{array}{l}0.352 \\
0.010\end{array}$ & $\begin{array}{l}0.342 \\
0.009\end{array}$ & $\begin{array}{l}0.329 \\
0.008\end{array}$ & $\begin{array}{l}0.351 \\
0.002\end{array}$ & $\begin{array}{l}0.351 \\
0.002\end{array}$ & $\begin{array}{l}0.356 \\
0.002\end{array}$ & $\begin{array}{l}0.355 \\
0.001\end{array}$ & $\begin{array}{l}0.361 \\
0.001\end{array}$ \\
\hline HbA1c & $\begin{array}{l}-0.152 \\
0.217\end{array}$ & $\begin{array}{l}-0.163 \\
0.161\end{array}$ & $\begin{array}{l}-0.153 \\
0.168\end{array}$ & $\begin{array}{l}-0.158 \\
0.150\end{array}$ & $\begin{array}{l}-0.155 \\
0.154\end{array}$ & $\begin{array}{l}-0.149 \\
0.165\end{array}$ & $\begin{array}{l}-0.164 \\
0.122\end{array}$ & $\begin{array}{l}-0.186 \\
0.082\end{array}$ \\
\hline TG & $\begin{array}{l}-0.304 \\
0.014\end{array}$ & $\begin{array}{l}-0.294 \\
0.013\end{array}$ & $\begin{array}{l}-0.287 \\
0.013\end{array}$ & $\begin{array}{l}-0.293 \\
0.010\end{array}$ & $\begin{array}{l}-0.288 \\
0.010\end{array}$ & $\begin{array}{l}-0.299 \\
0.007\end{array}$ & $\begin{array}{l}-0.300 \\
0.006\end{array}$ & $\begin{array}{l}-0.273 \\
0.012\end{array}$ \\
\hline $\begin{array}{l}\text { Peripheral } \\
\text { DBP }\end{array}$ & $\begin{array}{l}0.087 \\
0.597\end{array}$ & $\begin{array}{l}0.101 \\
0.516\end{array}$ & $\begin{array}{l}0.129 \\
0.323\end{array}$ & $\begin{array}{l}0.149 \\
0.225\end{array}$ & $\begin{array}{l}0.148 \\
0.222\end{array}$ & $\begin{array}{l}0.158 \\
0.187\end{array}$ & $\begin{array}{l}0.173 \\
0.142\end{array}$ & \\
\hline ACE-I & $\begin{array}{l}0.099 \\
0.396\end{array}$ & $\begin{array}{l}0.105 \\
0.354\end{array}$ & $\begin{array}{l}0.109 \\
0.328\end{array}$ & $\begin{array}{l}0.094 \\
0.372\end{array}$ & $\begin{array}{l}0.089 \\
0.394\end{array}$ & $\begin{array}{l}0.079 \\
0.440\end{array}$ & & \\
\hline HR & $\begin{array}{l}-0.199 \\
0.540\end{array}$ & $\begin{array}{l}-0.207 \\
0.517\end{array}$ & $\begin{array}{l}-0.207 \\
0.513\end{array}$ & $\begin{array}{l}-0.207 \\
0.508\end{array}$ & $\begin{array}{l}-0.211 \\
0.496\end{array}$ & & & \\
\hline ARB & $\begin{array}{l}0.057 \\
0.597\end{array}$ & $\begin{array}{l}0.056 \\
0.598\end{array}$ & $\begin{array}{l}0.065 \\
0.532\end{array}$ & $\begin{array}{l}0.062 \\
0.541\end{array}$ & & & & \\
\hline Age & $\begin{array}{l}-0.075 \\
0.635\end{array}$ & $\begin{array}{l}-0.071 \\
0.649\end{array}$ & $\begin{array}{l}-0.072 \\
0.642\end{array}$ & & & & & \\
\hline $\begin{array}{l}\text { Peripheral } \\
\text { SBP }\end{array}$ & $\begin{array}{l}0.060 \\
0.689\end{array}$ & $\begin{array}{l}0.048 \\
0.739\end{array}$ & & & & & & \\
\hline Insulin & $\begin{array}{l}-0.040 \\
0.748\end{array}$ & & & & & & & \\
\hline
\end{tabular}

Table 1. Regression models for determinants of eGFR in the DM group, Values are $B$ (upper line) and $P$ value (lower line)

\section{$2.3 \mathrm{CV}$ risk in ESRD}

Cardiovascular disease (CVD) is a common complication in end-stage renal disease (ESRD) with a 10 to 30 times greater CVD mortality compared to the general population[41]. Traditional CV risk factors while more prevalent, cannot fully explain this increased CV event rate in ESRD[28] and other factors including increased lipoprotein-a (lipo-a), adipokines, asymmetric dimethylarginine (ADMA), hyperhomocysteinemia, hyperparathyroidism and arterial stiffness have been implicated [27, 42-46]. In turn, arterial stiffness is affected by several hemodynamic and metabolic factors.

Diabetes mellitus (DM) is the leading cause of ESRD [43]. It is also a major CV risk. Despite medications and attempts to control these $\mathrm{CV}$ risk factors, $\mathrm{CV}$ events still remain the most 
common cause of mortality both in DM and in ESRD [47-49]. While a greater risk of CV events is expected in DM compared to non-DM patients with ESRD, the available reports regarding the risk profile in DM and non-DM patients with ESRD are conflicting [42, 43, 5053]. Likewise interactions between ESRD and DM in the development and progression of arterial stiffness are not completely clear [54,55]. As a result of several metabolic factors which contribute in arterial stiffening, vascular calcification is proposed as the fundamental phenomena in arterial stiffness and is certainly a frequent finding in ESRD and DM [56-58]. However the mechanisms for the development of vascular calcification are not completely understood. In particular, reports of its relationship with calcium homeostatic mechanisms including parathyroid hormone (PTH), phosphate and the calcium-phosphate product $(\mathrm{Ca} \times \mathrm{P})$ and vitamin $\mathrm{D}$ are inconsistent[58-62].

In an attempt to clarify classic and emerging risk factors in ESRD, we conducted a study of 100 diabetic and non-diabetic (paired matched for age and gender) individuals with ESRD and demonstrated blood pressure, heart rate, height and renal function as well as metabolic profiles, including cholesterol, homocystein, lipo(a) and CRP were comparable. However, carotid-femoral PWV (12.3 \pm 0.5 vs $10.3 \pm 0.2 ; \mathrm{P}<0.001)$ and pulse pressure $(71.2 \pm 2.2$ vs 64.2 \pm 2.4 ) were significantly greater in the DM group, despite a comparable AIx and waveform reflection time. Multivariate analysis demonstrated PTH to be a significant PWV determinant after adjustment for $\mathrm{DM}$, renal function and BP $(\mathrm{P}=0.038)$. As a particular novel finding, calcium-phosphate product had a u-shape association with central and peripheral PWV ( $\mathrm{P}<0.05)$, that is both low and high levels of calcium-phosphate product increases the $\mathrm{CV}$ risk in this group which was similar to its relationship with mortality, reported by Block et al. In conclusion, arterial stiffness as an established, independent and strong predictor of mortality in ESRD patients $[63,64]$ is possibly the factor that links cardiac and renal disease (Figure 3)[25]. Consequently, we proposed a model that can explain association of the factors (Figure 4 ).

\subsection{CV risk in kidney transplanted patients}

Kidney transplant patients have a lower risk of CVD compared to dialysis patients, even after controlling important source of selection bias including age[65]. However, CVD is still a common cause of post-transplant death [19]. Nevertheless, classic risk factors cannot fully explain the CV risk in this population. It is reported that the Framingham CV risk score significantly underestimates the risk of ischemic heart disease in transplant patients [66] and therefore, non-classic risk factors including C-reactive protein, homocystein and renal function as well as arterial stiffness may contribute in CV risk in this population $[67,68]$.

In support to the previously demonstrated findings our group studied 100 kidney transplanted patients (including $33 \mathrm{DM}$ ) and reported with a comparable classic CV risk factors, homocystein and renal function had a greater arterial stiffness when compared to non-DM. Also an improvement in central arterial stiffness was observed after a year of follow-up[69, 70]. This is in line with the other evidence that cardiac function in DM transplant candidates is carefully evaluated prior to transplantation and LV systolic, diastolic function and arterial compliance improves shortly after a successful renal transplant [71-75]. It was also concluded that assessment of arterial stiffness may improve pre-transplantation risk assessment both in donors and recipients[70]. 


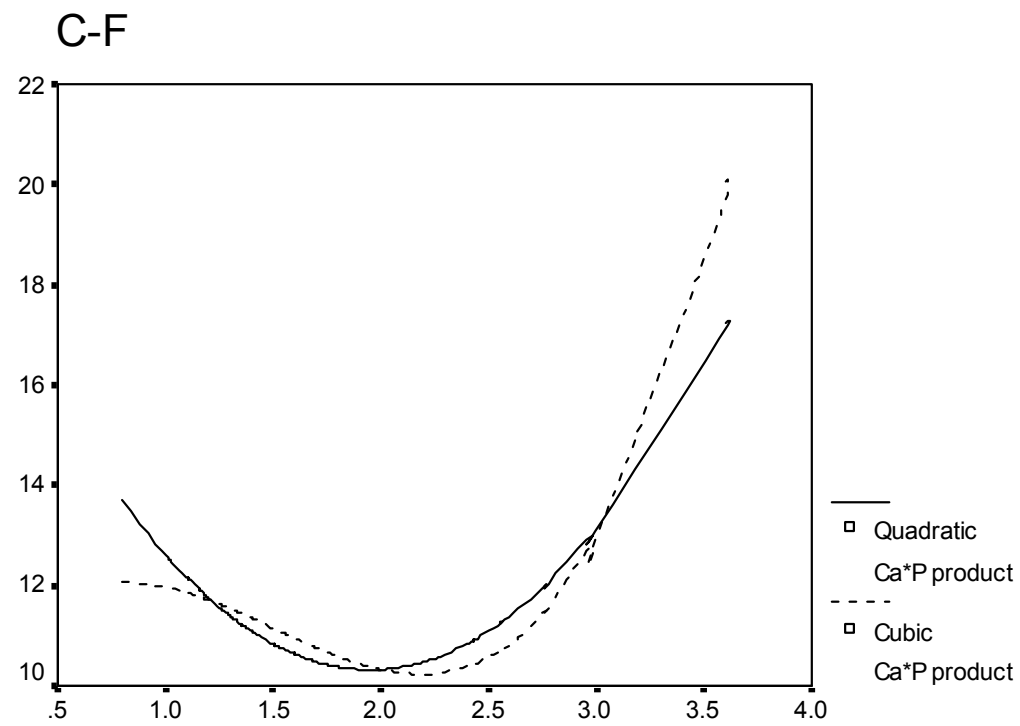

Ca*P product

\section{C-R}

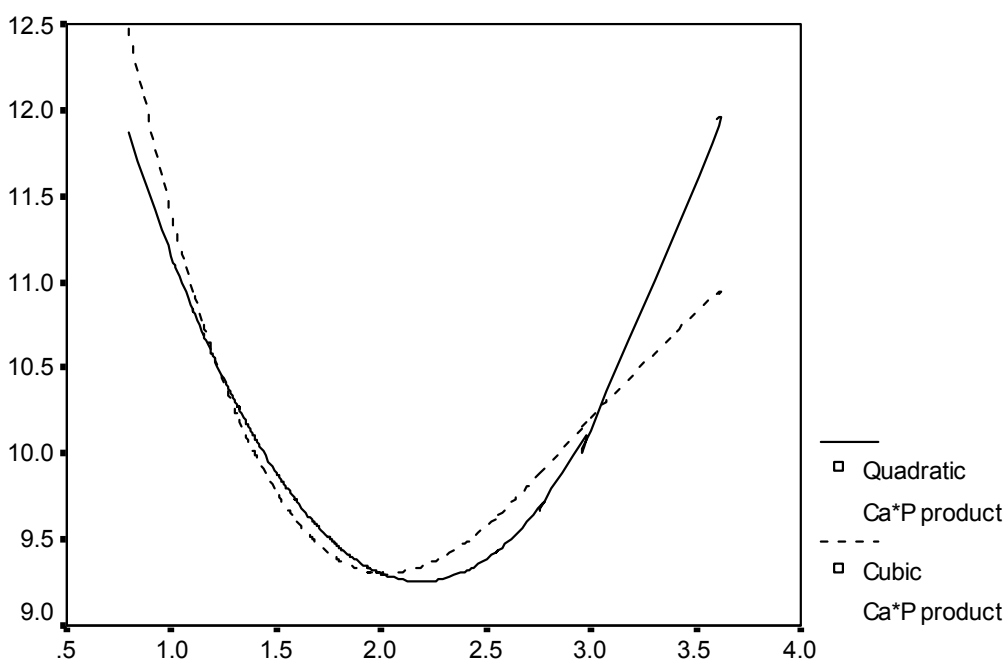

Ca*P product

Fig. 3. Non-linear relationship between central (left) and peripheral (right) pulse wave velocity with calcium-phosphorus product in ESRD 


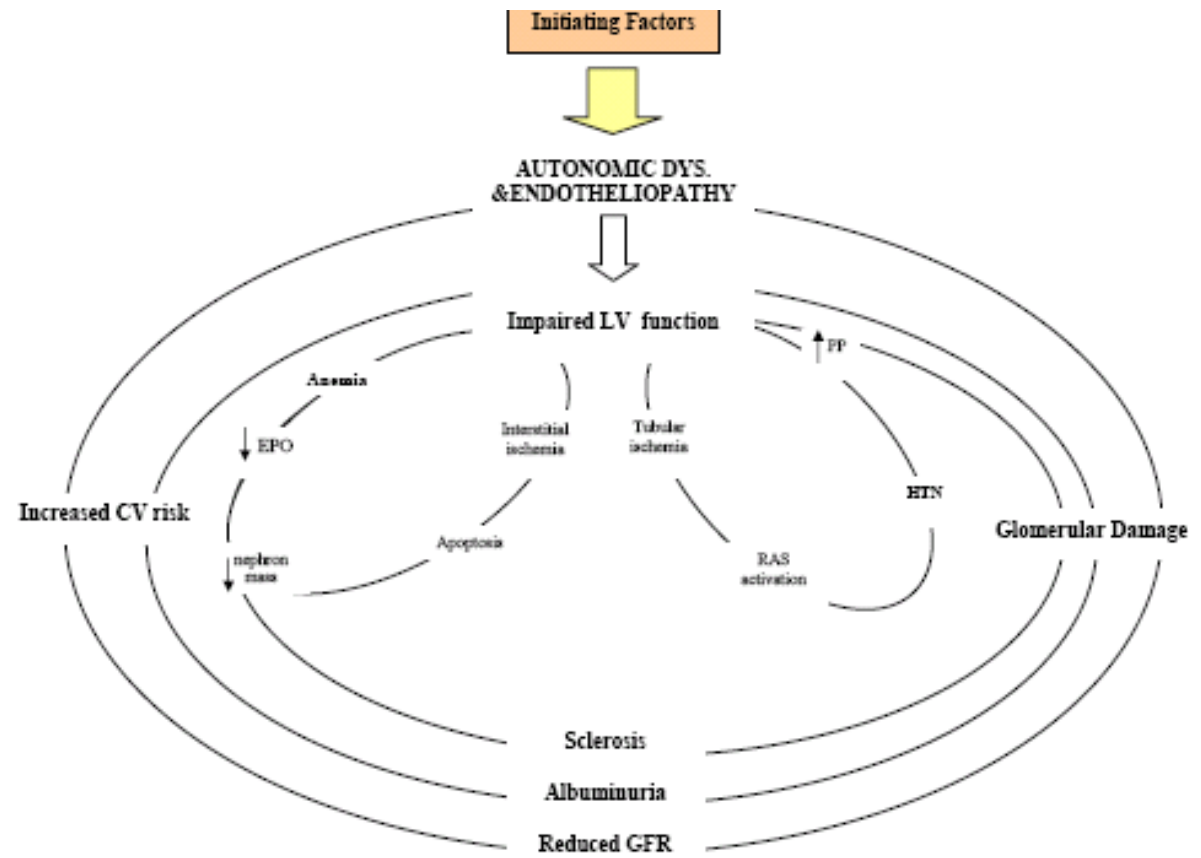

Fig. 4. Hypothetical model for explaining Renal-Cardiac Cross talk

\section{Fundamentals in CVD risk assessment}

The global epidemic of diabetes and chronic kidney diseases and their effect on the increased incidence of CVD, stresses on undeniable requirement for a timely effective CVD risk assessment in order to implement prevention strategies.

Risk assessment is a fundamental component of primary and secondary preventive strategies and an important skill in clinical epidemiology in particular for chronic diseases such as diabetes mellitus (DM) with potentially preventable multi-organ involvement. Although many risk factors have been identified as promoting DM complications, the presence of a risk factor only demonstrates the "risk" or the "possibility" of the given outcome since not all patients with the factor develop an adverse outcome and vice versa. However from a preventive point of view the medical approach is the attempted reduction of all risks factors so as to decrease this possibility. Nevertheless, decision thresholds are important determinants of risk factor management.

Traditionally, patients are assessed and managed based on the presence or absence of individual risk factors with a target point for each risk factor being determined and medical interventions (commonly by separate specialties) applied to achieve these targets. However, these risk factors also interact and can augment or diminish each others effect. In other words, patients with a particular risk factor might be more prone or more susceptible to be influenced by another risk factor. Moreover risk factors may have a synergistic effect thereby producing a greater impact beyond a summation of their individual risk. Accordingly, different target points have been assigned for various patient subgroups. For instance, 
recent practice guidelines suggested different target blood pressures for DM patients with and without proteinuria [76, 77]. Nevertheless, most risk factors such as BP have a linear relationship with the adverse outcome (i.e. CV events or mortality), even when levels are below the arbitrarily defined cut-off points[78, 79]. In an attempt to overcome this problem, new definitions such as pre-hypertension, pre-DM and pre-microalbuminuria have been added to recent practice guidelines [76, 77, 80], although they may have enhanced uncertainty and confusion rather than improve patient care.

While the target point approach appears to be straightforward, there may be a substantial risk of unnecessary treatment or neglect when treating certain patients. Consequently, a multifactorial risk assessment approach whereby a planned therapy is based on an individual's absolute risk is now encouraged [81]. This multidisciplinary approach is expected to be more effective, both medically and economically.

The simplest way to estimate a multifactorial global risk is to use the number of the present risk factors. For instance the number of present components of the metabolic syndrome associated with the risk of $\mathrm{CV}$ disease in DM or the development of renal impairment [82, 83]. Alternatively, each factor can be graded in an individual patient and scored (e.g. using the GCS in comatose diabetic patients) and then the total score is considered as representative of the severity of the condition and predictive for the outcome [84]. A more scientific approach would be to sort the factors according to their importance or the strength of their association and calculate a total risk or a "risk score" by summation of the weighted utilities of the factors. The appointed weight could be based on expert opinion or better still on more objective criteria. This technique should simulate the medical decision making process by a medical practitioner where the better the weighting the more accurate the diagnosis. Statistical methods including inferential analysis, discriminating analysis and probabilistic methods should facilitate this process. While multivariate analyses, including linear and logistic regression, are commonly used for this purpose, factor selection and modeling is the back bone of risk score development. Inappropriate modeling substantially damages the risk score performance [85]. Moreover, while the developed risk score can be ideally used in a similar population, it should not be extrapolated to other populations or even in the same population after a few years due to life style and risk factors changes, available medications or advanced diagnostic methods for the given outcome. Therefore, they must be repeatedly validated in the target population and re-evaluated to remain applicable in clinical practice. This process would yield an equation that would predict the outcome [86]. Although linear models are relatively simple and powerful methods for prediction, their essential assumptions including normality, independence and uniformity of variance must be fulfilled to be applicable [87]. Therefore, non-linear transformation is occasionally required and regression techniques can then be used to find the best discriminant function or decision boundary. However in most clinical situations many factors have equivocal discriminatory power and risk factors have interactions and clusters overlap. As a result the data space is multidimentional [86]. In these cases, intelligent systems including artificial neural networks can improve modeling and prediction. They provide a framework by selecting the most important discriminant items and appropriate form of boundaries [86, 88, 89]. Many [85] but not all [90,91] studies have reported that neural networks outperform conventional statistical methods. There are a few experiments of ANN application in clinical practice, including our innovative system for chronic kidney insufficiency that is already mentioned in this chapter. 


\section{Clustering CV risk factors: A critical appraisal}

In medical science, a "syndrome" is defined as an "aggregate of symptoms and signs or several conditions associated with any morbid process and constituted together they produce the picture of the disease" [92]. These components are usually caused by a unifying underlying pathology and their combination confers a risk that is different from the sum of the parts. The main purpose of such a description is to help in the diagnosis, treatment and prognosis of the disease.

The Metabolic Syndrome has been a useful construct in clinical practice as well as a valuable model to understand the interactions of diverse CV risk factors. However the concept has been critically appraised for its limited validity and clinical usefulness. This necessitates a novel model for a better and more effective risk assessment in clinical practice.

The metabolic syndrome was first described by G.M. Reaven in 1988 to describe a cluster of risk factors contributing to the incidence of diabetes mellitus (DM), cardiovascular (CV) events and also mortality[93]. The definition of this syndrome remains a matter of debate and has been revised on several occasions by different organisations [94-99]. Despite some diversity, obesity, hyperglycemia, dyslipidemia and hypertension have been constant syndrome components and the central concept of such descriptions is the unity of the background pathophysiologic process and the interaction between the elements. Several epidemiologic studies have illustrated the relationship between the metabolic syndrome, CV events and mortality[100-107]; however the syndrome was recently criticised by the American Diabetes Association for its modest consistency and limited clinical application[102] and the use of the term metabolic syndrome was discouraged. Furthermore, its clinical use has recently been described as artificial, confusing and ambiguous recast of traditional risk factors [108-111], with no advantage [110] and even more false positive rate in predicting diabetes and CV disease [112] compared to the usual Framingham risk assessment. In contrast, INTERHEART, a large worldwide prospective study demonstrated that the impact of risk factor clustering is much more than simply multiplying the risk of individual factors for acute myocardial infarction[113]. Although the general clinical strategy against the presence of each risk factor (either single or in combination with others) remains constant, the threshold of interventions may differ by accepting or denying the metabolic syndrome[114]. Hence, while the current definitions are controversial, evidence-based syndrome improvement must target better clinical applicability and higher predictive power of the modifiable outcomes.

Insulin resistance is presumed to be the common pathway for all features of the metabolic syndrome[115]; yet insulin related measurements are not standardized and vary widely [116, 117]. Furthermore, despite the widespread assumption among clinicians, hyperinsulinemia and insulin resistance are not equivalent terms[102]. Besides, while $78 \%$ of individuals with metabolic syndrome have insulin resistance, only $48 \%$ of patients with insulin resistance manifest the metabolic syndrome[118]. Consequently, Leptin resistance has been suggested as an alternative mechanism which also leads to hyperinsulinemia and other metabolic syndrome features [119].Therefore the association of hyperinsulinemia and other elements of this syndrome are not constant and many other factors may also play important roles as underlying mechanisms in clustering the risk factors. In other words, the metabolic syndrome is beyond insulin resistance, the phenomena which may simply be one of many abnormalities linked to a more fundamental, truly unifying pathophysiology [102, 
120]. Likewise, the metabolic syndrome diagnosis is not always associated with a higher CV risk, for example an increased risk was not observed in elderly diabetic and non-diabetic American Indians as well as women with suspected CV disease but normal angiography[121-123]. In addition the application of different syndrome definitions can cause a $15-20 \%$ disagreement in patient classification [102] thereby changing the predictive value of the syndrome diagnosis for CV disease and mortality [101, 106, 124]. This accumulating evidence demonstrates that the association of the current syndrome components with $\mathrm{CV}$ disease and with each other is uncertain. Even reports supporting the metabolic syndrome state that "detecting the metabolic syndrome is only one part of the overall $\mathrm{CV}$ risk assessment and is not an adequate tool to estimate the 10-year risk for coronary heart disease" [125]. This is probably due to the many other related factors not included as syndrome criteria. In fact, residual analysis of many longitudinal studies demonstrates a high unexplained variance (as much as $47 \%$ ) when metabolic syndrome components were considered as independent variables[102]. By and large, the current body of evidence strongly suggests that the metabolic syndrome definition needs to be standardized and additional factors included[114]. For example, despite several epidemiologic studies demonstrating the relationship between the metabolic syndrome and microalbuminuria, this factor was only incorporated into the World Health Organisation syndrome criteria in 1998 [126] which was not expressed in any other descriptions. Likewise renal failure, now accepted as an independent CV risk factor, as well as anaemia, have not been considered as a part of the metabolic syndrome. Moreover, the impact of endothelioarterial pathology has been overlooked and cardiac disease has been considered simply as an outcome and not an interacting part of the syndrome.

We have introduced the term of "circulatory syndrome" as a more refined clinical construct which is composed of many disease markers including Metabolic, Arterial, Renal and cardiac components (simply abbreviated as: "MARC")

\section{Circulatory (MARC) syndrome}

Circulatory syndrome is a cluster of risk markers with synergic effects. The proposed syndrome consists of eight major components (Figure 5), as follows (in the "MARC" order):

- Abnormal glucose metabolism

- Dyslipidemia

- Hypertension

- Arterial stiffness

- Microalbuminuria

- Renal impairment

- Anaemia

- Left ventricular dysfunction

All of these "markers" occur on a background of oxidative stress, inflammation, hypercoagulability and endotheliopathy (underlying factors) and can be accelerated by factors such as aging, obesity, smoking and physical inactivity (predisposing factors). Furthermore they can be simply and non-invasively assessed in outpatient clinical settings. While the mechanisms underlying the circulatory syndrome are poorly understood, it must be strongly stated that vascular-endothelial pathways link all and are of pathological 
significance. Activation of the renin-angiotensin system, insulin resistance and increased sympathetic activation are all by-products of the underlying pathogenic process. Since these markers represent the extent of the underlying disease process, they could also manifest as risk factors for other components and thereby enhance their development. Considering the interrelationships, the final outcome in this model can be considered to be CV events, stroke or renal failure; all of which are associated with general circulatory health. Consequently the condition of the circulatory system and these markers is directly related to the mortality rate.

Primordial studies demonstrate a robust and valid utility of the "MARC" syndrome concept and a useful risk assessment approach in chronic kidney disease and diabetes mellitus. However, larger prospective cohorts are required for further validation of the concept.

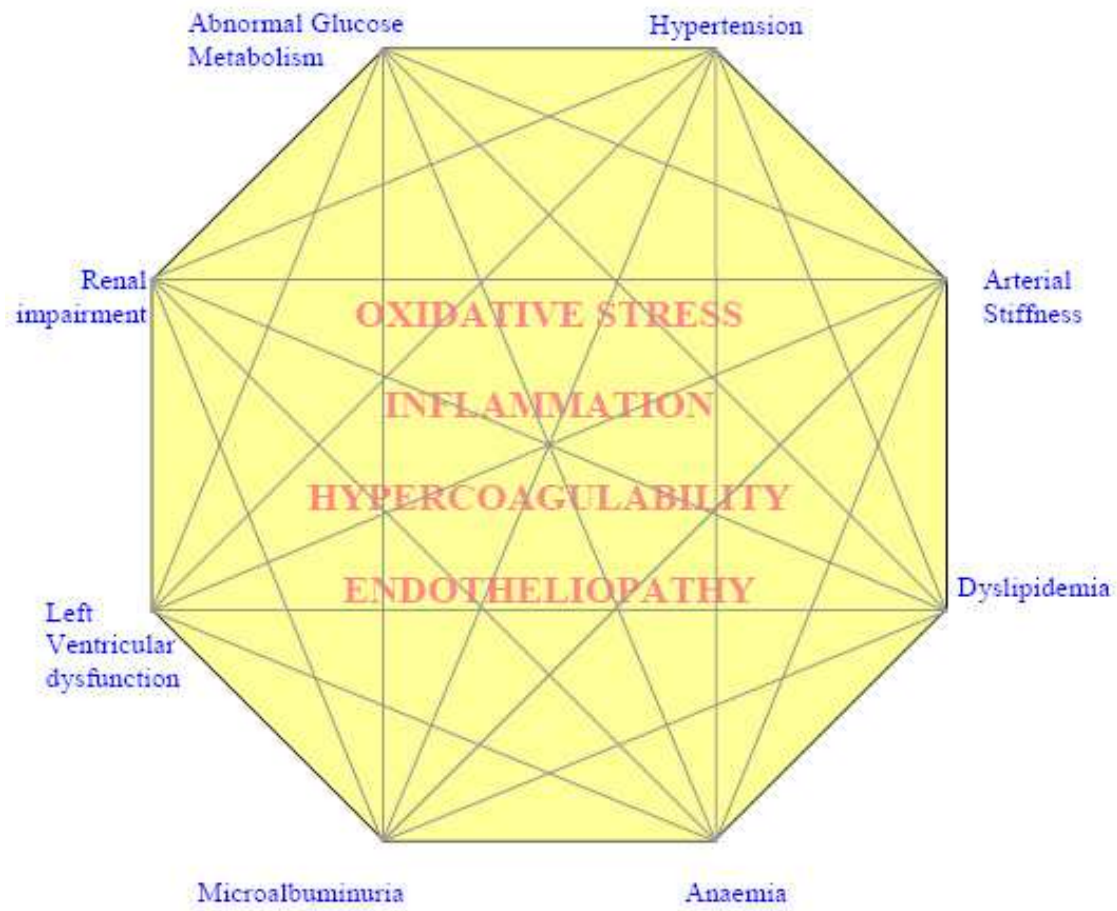

Fig. 5. An illustrative Circulatory Syndrome; A cluster of cardiac, renal, arterial and circulatory markers of disease that are interconnected through the endothelium; the common media (underlying factors) include oxidative stress, inflammation, hypercoagulability state and endotheliopathy which contribute in the main mechanisms of the phenomena; the third dimension (precipitating factors) include age, obesity, physical inactivity and smoking which accelerate the phenomena.

\section{Rationale For Inclusion Of The Components}

The Circulatory Syndrome shares some elements with the metabolic syndrome. However it includes additional metabolic and non-metabolic factors (Table2). 


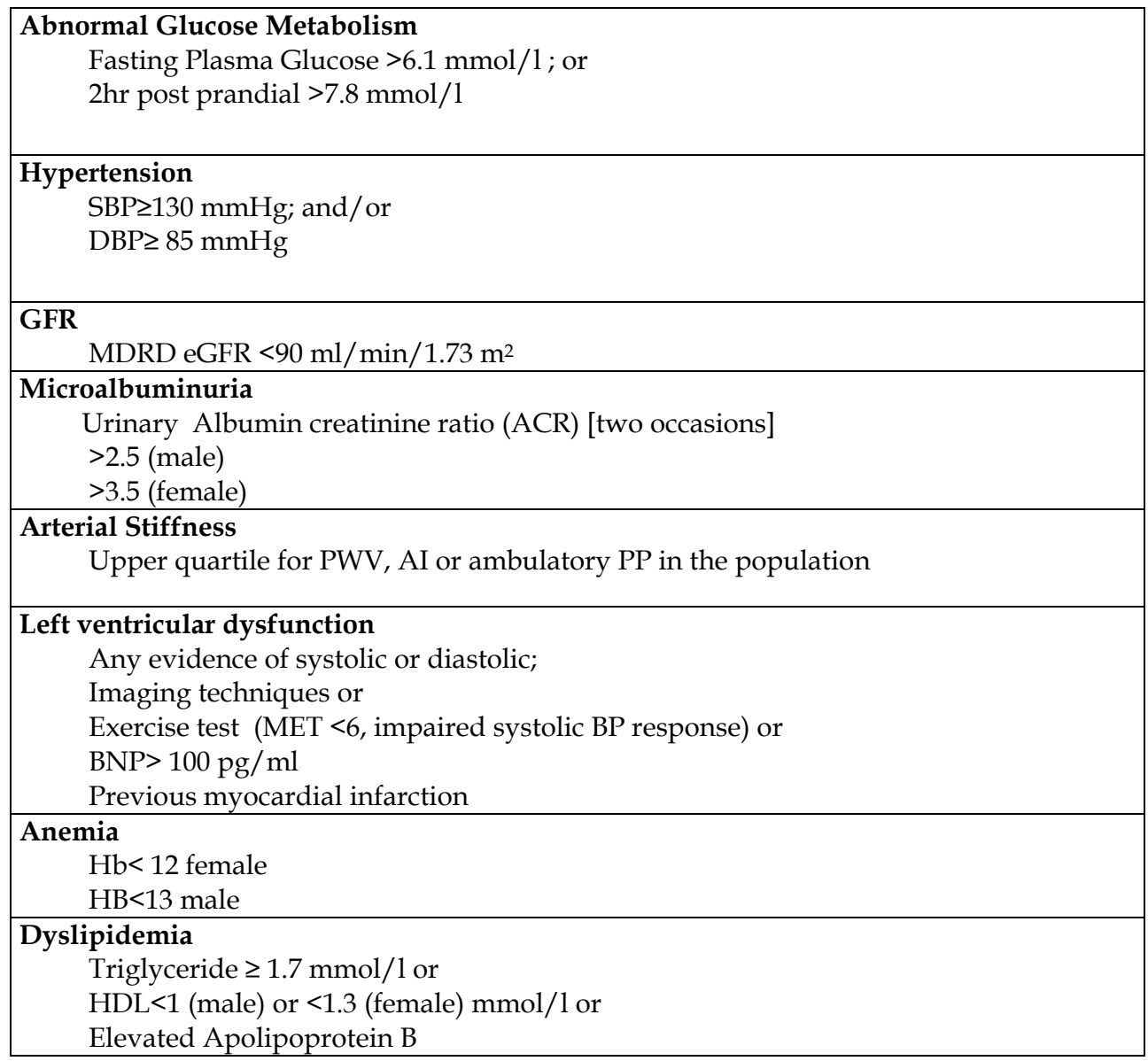

GFR: Glomerular Filtration Rate, PWV: Pulse Wave Velocity, AI: Augmentation Index, PP: Pulse Pressure, SBP: Systolic Blood Pressure, DBP: Diastolic Blood Pressure, MET: Estimated multiples of resting oxygen uptake, BNP: Brain Natriuretic Peptide, HDL: High Density Lipoprotein

Table 2. Preliminary Diagnostic Criteria for Circulatory Syndrome;

(1) Abnormal glucose metabolism: Diabetes and abnormalities in glucose metabolism are well known risk factors for cardiac, arterial and renal disease as well as anemia [127, 128]. Although insulin resistance and hyperinsulinemia can be attributed to these complications, they may occur with or without insulin resistance because several other mechanisms including advanced glycation end products, autonomic nervous instability, imbalance between the renin-angiotensin system and nitric oxide, hemodynamic changes and endothelial dysfunction with subsequent ADMA accumulation (an inhibitor for nitric oxide synthesis) and adiponectin deficiency also contribute in the process [120, 129, 130]. Furthermore, albuminuria, arterial stiffness and intima media thickness increase with the increasing number of metabolic syndrome components even before fulfilling the diagnostic criteria for the syndrome, particularly amongst subjects with type 2 DM [131]. In addition, 
alterations in BP circadian rhythm and BP profile including non-dipper nocturnal BP is now considered as a manifestation of arterial remodelling and is associated with other manifestation of endothelial dysfunction including $\mathrm{mA}$ and arterial stiffness.

(2) Lipid abnormalities: Dyslipidemia including increased LDL and TG as well as low HDL is a major risk in patients with chronic renal disease, hypertension and diabetes[105, 132134]. Genetic variants of lipoprotein lipase correlate with the presence and degree of albuminuria [135]. Dyslipidemia is an independent determinant of progression toward chronic kidney disease and is a known cardiac risk factor [28, 44]. It also contributes to arterial micro-inflammation and atherosclerosis[136]. From different perspective, the correction of lipid abnormalities can reduce albuminuria in subjects with the metabolic syndrome [137], decrease inflammatory markers[138], improve renal function[139], increase arterial compliance[140], improve left ventricular function [138] and prevent CV events[136]. It is noteworthy that obesity was not incorporated into our criteria since there is an opposite relationship between BMI and survival in CKD (reverse epidemiology) [108] and therefore less obese patients with CKD reach to ESRD.

(3) Blood pressure abnormalities: Hypertension is introduced as the leading risk factor of death according to WHO report of global health [4].Hypertension and altered blood pressure circadian rhythm are common co-morbidities with diabetes and pre-diabetic states as well as kidney disease[141]. BP is strongly associated with arterial stiffness and promotes left ventricular dysfunction[29]. In the setting of insulin resistance the vasodilatory effect of insulin can be lost but its renal sodium reabsorption stimulation is preserved. In addition, insulin-induced sympathetic activity increases the prevalence of hypertension in the metabolic syndrome [120]. Furthermore, while salt sensitivity is associated with impaired glucose metabolism, oxidative stress, dyslipidemia and insulin resistance $[142,143]$,it also increases efferent glomerular arteriolar tone and thereby raises glomerular capillary pressure and proteinuria [144] as well as inducing blood pressure abnormalities via renal sodium reabsorption and sympathetic overactivity[145].

(4) Arterial stiffness: Decreased arterial compliance is influenced by both atherosclerosis and arteriosclerosis, as well as functional arterial abnormalities [29, 146]. It occurs very early in the process of kidney disease and DM [147, 148], even preceding microalbuminuria [149] and has also been observed in normal individuals with a close family history of DM [148]. Recent studies have illustrated that increased central arterial stiffness in hypercholesterolemia, even in newly diagnosed individuals, is associated with low-grade systemic inflammation [150, 151]. Arterial stiffness in turn increases LV load and leads to ventricular stiffness and diastolic dysfunction [152,153]. It has also been suggested as the linking factor between renal impairment and CV diseases [25]. Of great importance, decreased arterial compliance predicts mortality in variant patient groups, independently from other risk factors [38, 154-156].

(5) Microalbuminuria is now accepted as a marker of renal, cardiac and arterial damage being predictive for the further development of CV events, renal failure and DM [25, 134]. It is also closely associated with the prevalence of anaemia [128], hypertension [157] and metabolic syndrome components [131]. Microalbuminuria commonly occurs early in subjects with abnormal glucose metabolism [147, 158] and is correlated with dyslipidemia [159], arterial stiffness[160, 161] and increased coagulability[162] as well as inflammatory 
markers[163, 164]. Furthermore the presence of microalbuminuria predicts ventricular dysfunction, coronary heart disease and exercise intolerance[165, 166].

(6) Renal impairment: Kidney function can not be isolated from the health of the heart and arteries and is also associated with the metabolic syndrome components. Alterations in glomerular structure are seen very early in the obesity-mediated metabolic syndrome[82] . Renal hemodynamic reserve is already impaired in patients with asymptomatic left ventricular dysfunction [167]. In addition, the kidney has an important role in insulin and glucose metabolism [168]and insulin resistance has a predictive value for chronic kidney disease [82, 95]. Renal function has been called the Cinderella shoe of CV risk profile [169] and the impact of even minor renal dysfunction on CV function is now well established [25] with endothelial cell dysfunction is likely to be the linking factor between renal and cardiac disease[25, 134, 170]. However endothelial dysfunction in turn is a consequence of inflammation and oxidative stress and is accelerated by these phenomena[171] and is also correlated with a number of the metabolic syndrome components [131]. Decreased arterial compliance increases ventricular wall tension and stiffness and consequently diastolic dysfunction[153]. This in turn may lead to partial renal ischemia, followed by activation of the renin-angiotensin system and tubulointerstitial damage[170]. On the other hand, hyperfiltration which is observed in the early stages of diabetic nephropathy and hypertension $[172,173]$, leads to increased glomerular pressure and resultant sclerosis which in turn accelerates hypertension[141].

(7) Anemia: Anemia is a common finding in DM and has multifactorial mechanisms[128]. Early tubulointerstitial occurs which disease decreases EPO production and moreover inflammatory cytokines reduce EPO responsiveness leading to anaemia[174]. It is also associated with the level of albuminuria[128]. Anaemia in turn, increases the progression toward CKD, oxidative stress, tissue ischemia, ventricular stress and mortality[175-177]. Of interest, a recent study demonstrated the contribution of anemia to the frequent diastolic dysfunction in DM, as well as its association with brain natriuretic peptide (BNP) and suggested using this factor to identify diabetic patients at increased risk of cardiac dysfunction [175]. Therefore, accumulating evidence has introduced anemia as an important risk factor for the circulatory system. On the other hand, correction of anemia improves the prognosis in chronic kidney disease, heart failure and DM and its complications as well as decreasing mortality [177-179]

(8) Left Ventricular dysfunction: In contrast to the metabolic syndrome, ventricular function is proposed as an interactive part of the circulatory syndrome. This idea is supported by reports of a lack of a relationship between the metabolic syndrome and mortality in individuals who have good cardiorespiratory fitness [180]. On the other hand even a mild stage of ventricular failure, as manifested by impaired exercise response is predictive for mortality[181, 182].Ventricular function determines blood pressure and renal perfusion and in turn is influenced by kidney function, anemia and arterial stiffness and microalbuminuria [153, 183]. Diastolic dysfunction occurs early in DM, is correlated with arterial stiffness and affects exercise response [184]. Furthermore, it has been reported that asymptomatic patients with type $2 \mathrm{DM}$ have subclinical ventricular dysfunction which is related to glycated hemoglubin and LDL cholesterol [185]. Also a recent in vitro study demonstrated that myocyte relaxation and $\mathrm{Ca}^{2+}$ handling are abnormal in early uremia, leading to uremic cardiomyopathy [186]. 
Additional evidence: It is of great interest that some hypoglycaemic agents reduce blood pressure via suppression of the renin-angiotensin system and some ACE inhibitors can reduce insulin resistance in addition to reducing microalbuminuria and arterial stiffness, which raises the possibility of the presence of a common pathway for the adverse effects of hyperglycemia and hypertension[187-189]. Likewise, some lipid lowering agents may exhibit mild anticoagulant and hypotensive effects [190] and angiotensin inhibitors have anti-inflammatory actions [191] which also indicate a possible common source of these abnormalities.

It could be expected that genetic predisposition including nephron underdosing, ACE gene polymorphism, congenital tubular defects and also some other factors such as aging, obesity and smoking produce organ damage susceptibility [133, 192-194].

The above evidence suggests that a genetic profile or a common pathologic process induces a network of metabolic (including alterations in glucose, salt, insulin and lipid metabolism) and hemodynamic abnormalities (due to renin-angiotensin system stimulation, sympathetic overactivity and decreased nitric oxide bioavailability) which are followed by anaemia, hypercoagulability, tissue ischemia, arterial stiffness, hypertension, renal and cardiac dysfunction, the other features of the circulatory syndrome (figure 5).

\section{Underlying Pathology}

It is proposed that inflammation is the fuel that "burns" the circulatory syndrome. The association between inflammatory markers and both DM and hypertension is so strong that these diseases has recently been redefined as inflammatory diseases, as has atheroma[195198]. Advanced glycation end products (AGEs) which accumulate in DM activate inflammatory cells[195]. Likewise, insulin resistance has a strong link with inflammation, although additional mechanisms including genetic factors may influence this relationship[199]. In addition, high LDL cholesterol induces oxidative stress and increases inflammation[200]. On the other hand HDL and apolipoprotein A1 have anti-inflammatory and anti-oxidant properties[201]. Hence, metabolic elements of the syndrome are correlated with inflammation.

Inflammation is known to be a modifier of the relationship between microalbuminuria and hypertension $[163,202]$. Hence, CRP has been frequently promoted as a part of the metabolic syndrome $[102,125,203]$. Moreover, inflammatory markers such as CRP are now considered to be independent predictors of DM [195] and its complications including left ventricular hypertrophy, endothelial dysfunction, albuminuria and renal failure [25, 171, 204, 205].

There is a close relationship between inflammation and hypercoagulability [164, 206]. Furthermore, hypercoagulability is also linked to the metabolic syndrome, dyslipidemia, anaemia and even the hemodynamic response to exercise [201, 207-209]. It is also associated with a poorer outcome in coronary artery disease, heart failure and is correlated with the severity of target-organ damage including renal impairment [210-212]. Consequently, diabetic and metabolic syndrome patients are at high risk for thrombotic events [213-215] and have an increased level of clotting factors including tissue plasminogen activator (tPA) and von Willenbrand Factor (vWF) and D-dimer when compared to the controls[216]. Additionally, insulin and lipids may have direct inhibitory effects on coagulation and platelet function through nitric oxide, a pathway that is impaired in DM patients [217]. 
By and large, this interlinking mesh of inflammatory mediators, oxidative stress, endotheliopathy and hypercoagulability makes a common soil for development of the circulatory (MARC) syndrome.

\section{New targets and novel approache to CVD risk modification}

The above description of the "circulatory syndrome" clearly has clinical applications. The identification of commonly evaluated markers such as blood pressure, glucose and lipids in a patient should also prompt a search for other markers which make up the circulatory syndrome. A suspected circulatory syndrome should facilitate decision making for diagnostic procedures in asymptomatic but high risk patients. Also treatment of each syndrome component should be accompanied by management of the other components. Furthermore, any difficulty in treating one circulatory syndrome marker should probably leads to a more aggressive treatment program for other components as is currently proposed in patients with renal disease, diabetes and associated hypertension. Hence, management of the proposed "Circulatory Syndrome" would need an interdisciplinary approach with the collaboration of different medical subspecialties.

\section{A novel approach to diabetic nephropathy (DN)}

The evidence of the close relationship of DM, hypertension, renal function, cardiac function, arterial compliance and metabolic factors have already been discussed. Accordingly the proposed concept of the "Circulatory Syndrome" could be applied as a novel approach to DN. This approach should overcome the potential barriers to achieving target points in DM and enhance medications efficacy. According to this new perspective, the treatment of comorbidities in DM including heart failure, renal failure, arterial stiffness, anemia and the hypercoagulability state as well as reducing any potential inflammation source (e.g. chronic infections, immunology-mediated disease and sensitivities) should enhance adherence to the target points and disease control. This needs a "multidisciplinary approach" to CV risk management in DM, in which a clinical epidemiologist or a care plan manager must have a central role. Additionally a global risk score is preferred to the current target points for each risk factor so that the threshold of intervention is clearly defined based on several potential risk factors and assessment of adherence to the guideline is estimated by risk score alterations.

\section{New markers}

Given the serious limitations of using $\mathrm{mA}$ as a single disease marker in screening [31], a multifactorial approach is required to boost screening efficacy and allow reliable risk estimation in DN. The Japanese Society of Nephrology is the only professional organization that has formally added renal hypertrophy and urinary type IV collagen to their guideline as early markers of the existence of DN [218]. There is also evidence for other potential markers including glomerular, tubular, interstitial, endothelioarterial, genetic and cellular markers. However their applicability, validity and reliability must be investigated in a parallel test with $\mathrm{mA}$.

These markers help risk stratification for patients without $\mathrm{mA}$ or with fluctuating proteinuria. Furthermore, they facilitate diagnosis of other facets of diabetic kidney damage and also explain the link between cardiac and renal complications of DM. 


\section{New strategies}

The threshold of action for screening, intervention and assessment must be revised based on current DN knowledge and should be followed by altered strategies to define high risk patients. It should also include all pathological aspects of DN including those proposed in the "Circulatory Syndrome", although these will need to be refined, particularly in asymptomatic patients.

In terms of treatment, research findings about renal benefits of the renin-angiotensinaldosterone system (RAAS) blocking irrespective of blood pressure and albuminuria [219] have not fully integrated into Clinical practice guidelines. Likewise, while recent research has demonstrated advantages of lipid lowering agents even in patients with normal lipid levels [220], the threshold for action remains at higher levels. Similarly, treating anemia has a significant impact on renal function preservation even in early stages of renal disease and erythropoietin therapy has potential advantages for cardiac, neural, endothelial and renal protection [221] as well as a general benefits due to reduction in the oxidative stress, insulin resistance and cytokine accumulation in DM patients (as mentioned in our recently published paper [222]); yet decision criteria are not completely clear in this regard. With accumulating evidence, the threshold for anemia correction is expected to be reduced in a near future.

Regarding follow-up, recent reliable and practical assessments should be considered including central and/or ambulatory BP. Also for renal function, eGFR (based on the MDRD or the Cockcroft-Gault formula) is superior to plasma creatinine [223].

\section{New treatment targets}

It might be argued that with considering the circulatory syndrome concept and increasing number of the action sites, the number of medication is ought to be increased. Then since increased number of medications usually leads to reduced patients' compliance, such an approach may not only fail to improve disease control, but also make the problem more complex. While possibly true, there are potential solutions. For instance many experts encourage "poly-pills" which include a combination of the required agents. Although it may have better patients' acceptance, it cannot reduce the potential adverse effect of polypharmacy. Alternatively and ideally, the type of treatment must be revised in order to meet multiple targets using a single medication ("super-pills").

New treatment options: The marked advantages of using ACE-I and ARB has been appreciated with a $60-70 \%$ risk reduction the risk of progression to overt nephropathy in several large clinical trials [224-226]. However this optimistic result would not be completely achieved in routine practice and they can not abrogate the progression of kidney disease. This may suggest incomplete blockage of the RAAS by current medication dose which allow "aldosterone synthesis escape"[227]. Although a recent meta-analysis of randomized trials with ACE-Is and ARBs yielded only a small renoprotection benefit (and no benefit in DM) and demonstrated a smaller benefit in large studies [228], it contradicts previous metaanalysis [229, 230] and seems to be biased by the accessory results from the Antihypertensive and Lipid Lowering treatment to prevent Heart attack Trial (ALLHAT) which was not originally designed for renal outcome evaluation [231]. 
A combination with beta blockers or calcium channel blockers or a diuretic was previously recommended in the practice guidelines, newer combinations of ACE-I and indapamide, ACE-I and spirinolactone and a double blockage of RAAS (ACE-I and ARB) have been demonstrated promising in terms of lowering $\mathrm{BP}$ and $\mathrm{mA}$, which is also supported by the new understanding of ACE-2 enzyme, angiotensin recptor- 2 and the role of aldosterone in CKD progression [232] In addition, using pioglitazone or rosiglitazone in combination with sulphonylurea with or without metformine has also been suggested by experts as an effective combination; however the available clinical data is still limited. Finally, it is noteworthy that while identification and management of hypertensive patients with elevated heart rate (with beta-blockers or calcium antagonists)is recommended by expert consensus [233], non-selective beta blockers (e.g. propranolol) generally decrease GFR by lowering cardiac output. In contrast, the 131 -selective agents (e.g. metoprolol and atenolol) may have a beneficial effect on declining GFR as well as protecting heart against heart failure. However these may also have adverse effect on plasma glucose and atenolol must be adjusted in renal failure due to its impaired renal clearance. On the other hand non-selective vasodilating beta blockers (Carvedilol and Labetalol) not only reduce BP but also have antioxidant and renoprotective effects [234]. Finally, considering of erythropoietine (EPO) in medical management of diabetes is expected to improve CV health in DM $[222,235]$.

New agents: Several animal models have suggested many potential candidates for prevention and treatment of DN. Renoprotective effect of ALT-711 (a cross link breaker of the advance glycosylation end product), ruboxistaurin (an inhibitor for protein kinase C), eplerenone (a new aldosterone antagonist), thiamine and a modified heparin glycosaminoglycan have been reported, as being effective in reducing albuminuria and renal lesions [232, 236, 237]. However, very few human studies have been conducted in human of which the combination of ACE-I and omepatrilat (an endopeptidase inhibitor), sulodexide (a glycosaminoglycan), Pirfenidone (TGF- $\$$ inhibitor) and pimagedine (a second generation inhibitor of advanced glycation end product) have had dramatic beneficial effects in DM patients [232, 236, 238]. There are also some evidence of the efficacy of folic acid on endothelial function improvement in different groups of patients including type 2 DM [239].

Developing novel drugs opposing the action of TGF- $B$, connective tissue growth factors, cytokines and reactive oxygen species is the next step. Also by recognizing the role of relaxin [240], urotensin II [241] and vascular calcification contributors, additional medication might one day be available.

Multipotential agents: Accumulating evidence demonstrates the polydimentional action of some medications on glycaemic and BP control, reducing lipid and $\mathrm{mA}$ and improvement in arterial compliance. For instance, blocking of the renin-angiotensin system has anti-diabetic and anti-inflammatory effects as well as antihypertensive actions and improves $\mathrm{mA}$ and arterial stiffness at the same time [187, 189, 191]. This also applies to some lipid lowering agents [190, 220]. Likewise, insulin-sensitizing thiazolidinediones (TZDs) ameliorate mA and are antihypertensive [242]. Also metformin improves both endothelial function and the metabolic syndrome [243]. From a different point of view, treating anemia with erythropoietin may also have cardiac, renal, neurohormonal and metabolic benefits due to anemia correction of anemia and the cytoprotective effects of erythropoietin perse [221, 222, 244]. Several researches are being conducted to introduce and develop novel EPO replacement therapies such as synthetic erythropoietic proteins, continuous EPO receptor 
activators (CERA), EPO gene transfer using retroviral vectors and implementation of EPO producing cells in A-V fistula graft which will create a revolution in related therapies [222].

With the axial role of RAAS in the pathogenesis of DN, non-hemodynamic effects of ACE-I and ARB including their action on TGF- $B$, extracellular matrix and cytokines have the focus of several studies in recent years [237]. According to a recent study Losartan improves resistance artery lesions and prevents TGF- $\beta$ production in untreated hypertensive patients [245]. In addition, ACE-I agents potentiate bradykinin-induced tissue plasminogen activator (t-PA) release leading to endothelial fibrinolytic function [246, 247]. Consequently several studies have indicated that the renoprotective of these drugs is independent of their antihypertensive effect [229].

The recognition of a new class of nuclear receptors named "peroxisome proliferatorsactivated receptor" (PPAR) has provided an additional field for action against DN and consequently its CV complications. Rosiglitazone is a PPAR- $\gamma$ agonist which was demonstrated as being effective in lowering blood pressure and reversing insulin resistance [248]. Likewise, several studies have verified the multipotential action of PPAR-a agonists including Fenofibrate in reducing fasting blood glucose, ameliorating insulin resistance, decreasing $\mathrm{mA}$, correction of lipid metabolism, suppressing collagen by mesangeal cells, preventing glomerulosclerosis as well as antihypertensive [242, 249]. This body of evidence supports the potential impact of multipotential drugs in the future treatment of DN.

\section{Conclusion}

Early diagnosis and management of CV risk, particularly in diabetes and chronic kidney disease requires a new insight and subsequently a novel approach to the disease is mandatory. While our studies demonstrated various facets of the interactions between renal, cardiac, arterial and metabolic factors, the proposed "Circulatory Syndrome" can facilitate formulation of new strategies for the better diagnosis and management of CV risk. Accordingly, a multidisciplinary evaluation of glycemic control, lipids, anemia, blood pressure profile, albuminuria, GFR and ventricular function as well as an assessment of arterial compliance (as an axial element) provides adequate information for early and effective identification of high risk patients for progression toward CVD. The proposed concept of the "Circulatory (MARC) Syndrome" is expected to facilitate this revolution by a multidisciplinary approach.

\section{References}

[1] Gersh, B., K. Sliwa, B. Mayosi, et al., The epidemic of cardiovascular disease in the developing world: global implications. Eur Heart J, 2010. 31: p. 642-648.

[2] Preis, S., M. Pencina, S. Hwang, et al., Trends in Cardiovascular Disease Risk Factors in Individuals With and Without Diabetes Mellitus in the Framingham Heart Study. Circulation, 2009. 120: p. 212-20.

[3] Khoshdel, A.R. Hemodynamic response to exercise predicts the development of severe renal failure. in International Society of Nephrology. 2007. Rio, Brazil.

[4] Global Health Risks: Morbidity and burden of disease attributable to selected major risks. WHO Global Reports. 2009. 70. 
[5] Mukamal, K., R. Kronmal, R. Tracy, et al., Traditional and novel risk factors in older adults: cardiovascular risk assessment late in life. Am J Geriatr Cardiol, 2004. 13(2): p. 69-80.

[6] Gu, K., C.C. Cowie, and M.I. Harris, Diabetes and decline in heart disease mortality in US adults. Jama, 1999. 281(14): p. 1291-7.

[7] $\mathrm{Gu}, \mathrm{K} .$, C.C. Cowie, and M.I. Harris, Mortality in adults with and without diabetes in a national cohort of the U.S. population, 1971-1993. Diabetes Care, 1998. 21(7): p. 113845.

[8] Shange, Q. and G. Yip, Diabetic heart disease: the story continues. Journal of Human Hypertension, 2011. 25: p. 141-143.

[9] Grundy, S.M., B. Howard, S. Smith, Jr., et al., Prevention Conference VI: Diabetes and Cardiovascular Disease: executive summary: conference proceeding for healthcare professionals from a special writing group of the American Heart Association. Circulation, 2002. 105(18): p. 2231-9.

[10] Impact of diabetes on cardiovascular disease risk and all-cause mortality in older men: influence of age at onset, diabetes duation and established and novel risk factors. Arch Intern Med, 2011. 171(5): p. 404-10.

[11] Gibbons, R.J. and E.M. Antman, ACC/AHA 2002 Guideline Update For Exercise Testing, in ACC/AHA Practice Guidelines. 2002, American College of Cardiology; American Heart Association: Bethesda, USA.

[12] Stewart, K.J., J. Sung, H.A. Silber, et al., Exaggerated Exercise Blood Pressure is related to impaired endothelial vasodilator function. American Journal of Hypertension, 2004. 17: p. 314-320.

[13] Bell, D.S.H., Heart Failure: A serious and common comorbidity of diabetes. Clinical Diabetes, 2004. 22(2): p. 61-5.

[14] Khoshdel, A., S. Carney, and s. White. Disturbed Hemodynamic Cardiac Exercise Stress Test Reponse in non-smoking, Normolipidemic, Normotensive Diabetic Subjects. in Cardiovascular disease in the 21st century: Shaping the future. 2006. Sydney.

[15] Khoshdel, A.R., S.L. Carney, and S. White, Disturbed hemodynamic cardiac exercise stress test response in non-smoking, normolipidemic, normotensive, diabetic subjects. Diabetes Res Clin Pract, 2007. 75(2): p. 193-9.

[16] Khoshdel, A.R. and S.L. Carney. HEMODYNAMIC RESPONSE TO EXERCISE PREDICTS THE DEVELOPMENT OF SEVERE RENAL FAILURE. in 14th World Congress on Heart Disease. 2008. Toronto, CANADA, July 2008: American Heart Association.

[17] Khoshdel, A. and S. Carney, Wrist cuff blood pressure self-measurement in diabetic patients: comparable to ambulatory blood pressure monitoring. Hypertension, 2006. 49(6): p. 1470.

[18] Khoshdel, A.R., Circulatory syndrome a new insight into the early diagnosis and management of renal-cardiovascular risk in diabetes mellitus, in School of Medicine and Public Health. 2007, University of Newcastle (N.S.W.). Newcastle. p. 356.

[19] McDonald, S. and L. Excell, Australia and New Zealand Dialysis and Transplant Registry (28th report), ed. K.H.A. Commonwealth Department of Health and Ageing, New Zealand Ministry of Health. 2005.

[20] Haghighi, A.N., B. Broumand, M. D'Amico, et al., The epidemiology of end-stage renal disease in Iran in an international perspective. Nephrol Dial Transplant, 2002. 17(1): p. 28-32.

[21] Feest, T.G., J. Rajamahesh, C. Byrne, et al., Trends in adult renal replacement therapy in the UK: 1982-2002. Qjm, 2005. 98(1): p. 21-8. 
[22] Barsoum, R.S., Chronic kidney disease in the developing world. N Engl J Med, 2006. 354(10): p. 997-9.

[23] Rutkowski, B., Changing pattern of end-stage renal disease in central and eastern Europe. Nephrol Dial Transplant, 2000. 15(2): p. 156-60.

[24] Friedman, E.A., ESRD in diabetic persons. Kidney International, 2006. 70: p. S51-54.

[25] Ritz, E., Heart and kidney: fatal twins? Am J Med, 2006. 119(5 Suppl 1): p. S31-9.

[26] London, G., Cardiovascular disease in end-stage renal failure: role of calcium-phosphate disturbances and hyperparathyroidism. J Nephrol, 2002. 15(2): p. 209-10.

[27] Zoccali, C., Traditional and emerging cardiovascular and renal risk factors: an epidemiologic perspective. Kidney Int, 2006. 70(1): p. 26-33.

[28] Zoccali, C., Cardiorenal risk as a new frontier of nephrology: research needs and areas for intervention. Nephrol Dial Transplant, 2002. 17 Suppl 11: p. 50-4.

[29] Vlachopoulos, C. and M. O'Rourke, Genesis of the normal and abnormal arterial pulse. Curr Probl Cardiol, 2000. 25(5): p. 303-67.

[30] Massry, S.G. and R.J. Glassock, Textbook of Nephrology. 2001, Philadelphia: Lippincott Williams. 876.

[31] Caramori, M.L., P. Fioretto, and M. Mauer, The need for early predictors of diabetic nephropathy risk: is albumin excretion rate sufficient? Diabetes, 2000. 49(9): p. 1399-408.

[32] Taal, M.W. and B.M. Brenner, Predicting initiation and progression of chronic kidney disease: Developing renal risk scores. Kidney Int, 2006. 70(10): p. 1694-705.

[33] MacIsaac, R.J., S. Panagiotopoulos, K.J. McNeil, et al., Is nonalbuminuric renal insufficiency in type 2 diabetes related to an increase in intrarenal vascular disease? Diabetes Care, 2006. 29(7): p. 1560-6.

[34] Tabaei, B.P., A.S. Al-Kassab, L.L. Ilag, et al., Does microalbuminuria predict diabetic nephropathy? Diabetes Care, 2001. 24(9): p. 1560-6.

[35] Kramer, H.J., Q.D. Nguyen, G. Curhan, et al., Renal insufficiency in the absence of albuminuria and retinopathy among adults with type 2 diabetes mellitus. Jama, 2003. 289(24): p. 3273-7.

[36] Perkins, B.A., L.H. Ficociello, K.H. Silva, et al., Regression of microalbuminuria in type 1 diabetes. N Engl J Med, 2003. 348(23): p. 2285-93.

[37] Guerin, A.P., J. Blacher, B. Pannier, et al., Impact of aortic stiffness attenuation on survivial of patients in end-stage renal failure. Circulation, 2001. 20: p. 987-92.

[38] London, G.M., J. Blacher, B. Pannier, et al., Arterial wave reflections and survival in endstage renal failure. Hypertension, 2001. 38(3): p. 434-8.

[39] London, G.M. and J.N. Cohn, Prognostic application of arterial stiffness: task forces. Am J Hypertens, 2002. 15(8): p. 754-8.

[40] Khoshdel, A.R., S.L. Carney, B.R. Nair, et al., Better management of cardiovascular diseases by pulse wave velocity: combining clinical practice with clinical research using evidencebased medicine. Clin Med Res, 2007. 5(1): p. 45-52.

[41] Sarnak, M.J., A.S. Levey, A.C. Schoolwerth, et al., Kidney disease as a risk factor for development of cardiovascular disease: a statement from the American Heart Association Councils on Kidney in Cardiovascular Disease, High Blood Pressure Research, Clinical Cardiology, and Epidemiology and Prevention. Circulation, 2003. 108(17): p. 2154-69.

[42] Cheung, A.K., M.J. Sarnak, G. Yan, et al., Atherosclerotic cardiovascular disease risks in chronic hemodialysis patients. Kidney Int, 2000. 58(1): p. 353-62.

[43] Sasso, F.C., L. De Nicola, O. Carbonara, et al., Cardiovascular risk factors and disease management in type 2 diabetic patients with diabetic nephropathy. Diabetes Care, 2006. 29(3): p. 498-503. 
[44] Locatelli, F., J. Bommer, G.M. London, et al., Cardiovascular disease determinants in chronic renal failure: clinical approach and treatment. Nephrol Dial Transplant, 2001. 16(3): p. 459-68.

[45] Thomas, S.M. and G.C. Viberti, Cardiovascular risk in diabetic kidney disease: a model of chronic renal disease. Kidney Int Suppl, 2005(98): p. S18-20.

[46] Metabolic syndrome, chronic kidney and cardiovascular diseases: role of adipokines. Cardiol Res Prac, 2011.

[47] Morrish, N.J., S.L. Wang, L.K. Stevens, et al., Mortality and causes of death in the WHO Multinational Study of Vascular Disease in Diabetes. Diabetologia, 2001. 44 Suppl 2: p. S14-21.

[48] Racki, S., L. Zaputovic, B. Vujicic, et al., Comparison of survival between diabetic and nondiabetic patients on maintenance hemodialysis: A single-centre experience. Diabetes Res Clin Pract, 2006.

[49] Rossing, K., P.K. Christensen, P. Hovind, et al., Progression of nephropathy in type 2 diabetic patients. Kidney Int, 2004. 66(4): p. 1596-605.

[50] Wheeler, D.C., J.N. Townend, and M.J. Landray, Cardiovascular risk factors in predialysis patients: baseline data from the Chronic Renal Impairment in Birmingham (CRIB) study. Kidney Int Suppl, 2003(84): p. S201-3.

[51] Shinohara, K., T. Shoji, Y. Tsujimoto, et al., Arterial stiffness in predialysis patients with uremia. Kidney Int, 2004. 65(3): p. 936-43.

[52] Blacher, J., K. Demuth, A.P. Guerin, et al., Influence of biochemical alterations on arterial stiffness in patients with end-stage renal disease. Arterioscler Thromb Vasc Biol, 1998. 18(4): p. 535-41.

[53] Ishimura, E., S. Okuno, K. Kitatani, et al., Different risk factors for peripheral vascular calcification between diabetic and non-diabetic haemodialysis patients-importance of glycaemic control. Diabetologia, 2002. 45(10): p. 1446-8.

[54] Shoji, T., M. Emoto, K. Shinohara, et al., Diabetes Mellitus, Aortic Stiffness, and Cardiovascular mortality in End-Stage Renal disease. J Am Soc Nephrol, 2001. 12: p. 2117-24.

[55] Aoun, S., J. Blacher, M.E. Safar, et al., Diabetes mellitus and renal failure: effects on large artery stiffness. J Hum Hypertens, 2001. 15(10): p. 693-700.

[56] Floege, J. and M. Ketteler, Vascular calcification in patients with end-stage renal disease. Nephrol Dial Transplant, 2004. 19 Suppl 5: p. V59-66.

[57] Goodman, W.G., Vascular calcification in chronic renal failure. Lancet, 2001. 358(9288): p. 1115-6.

[58] London, G.M., A.P. Guerin, S.J. Marchais, et al., Arterial media calcification in end-stage renal disease: impact on all-cause and cardiovascular mortality. Nephrol Dial Transplant, 2003. 18(9): p. 1731-40.

[59] Smith, J.C., M.D. Page, R. John, et al., Augmentation of central arterial pressure in mild primary hyperparathyroidism. J Clin Endocrinol Metab, 2000. 85(10): p. 3515-9.

[60] Rubin, M.R., M.S. Maurer, D.J. McMahon, et al., Arterial stiffness in mild primary hyperparathyroidism. J Clin Endocrinol Metab, 2005. 90(6): p. 3326-30.

[61] Chow, K.M., C.C. Szeto, and P.K. Li, Parathyroid hormone and mineral metabolism do not have significant impact on pulse pressure in patients undergoing peritoneal dialysis. Clin Nephrol, 2003. 60(4): p. 266-9. 
[62] Suzuki, T., K. Yonemura, Y. Maruyama, et al., Impact of serum parathyroid hormone concentration and its regulatory factors on arterial stiffness in patients undergoing maintenance hemodialysis. Blood Purif, 2004. 22(3): p. 293-7.

[63] Blacher, J., M.E. Safar, A.P. Guerin, et al., Aortic pulse wave velocity index and mortality in end-stage renal disease. Kidney Int, 2003. 63(5): p. 1852-60.

[64] Safar, M.E., J. Blacher, B. Pannier, et al., Central pulse pressure and mortality in end-stage renal disease. Hypertension, 2002. 39: p. 735-8.

[65] Wolfe, R.A., V.B. Ashby, E.L. Milford, et al., Comparison of mortality in all patients on dialysis, patients on dialysis awaiting transplantation, and recipients of a first cadaveric transplant. N Engl J Med, 1999. 341(23): p. 1725-30.

[66] Kasiske, B.L., H.A. Chakkera, and J. Roel, Explained and unexplained ischemic heart disease risk after renal transplantation. J Am Soc Nephrol, 2000. 11(9): p. 1735-43.

[67] Barenbrock, M., M. Kosch, E. Joster, et al., Reduced arterial distensibility is a predictor of cardiovascular disease in patients after renal transplantation. J Hypertens, 2002. 20(1): p. 79-84.

[68] Marcen, R., Cardiovascular risk factors in renal transplantation--current controversies. Nephrol Dial Transplant, 2006. 21 Suppl 3: p. iii3-8.

[69] Khoshdel, A.R. and S.L. Carney, Arterial stiffness in kidney transplant recipients: an overview of methodology and applications. Urol J, 2008. 5(1): p. 3-14.

[70] Khoshdel, A.R., S.L. Carney, P. Trevillian, et al., Evaluation of arterial stiffness and pulse wave reflection for cardiovascular risk assessment in diabetic and nondiabetic kidney transplant recipients. Iran J Kidney Dis, 2010. 4(3): p. 237-43.

[71] Dudziak, M., A. Debska-Slizien, and B. Rutkowski, Cardiovascular effects of successful renal transplantation: a 30-month study on left ventricular morphology, systolic and diastolic functions. Transplant Proc, 2005. 37(2): p. 1039-43.

[72] Nakajima, K., T. Ochiai, T. Suzuki, et al., Beneficial effects of renal transplantation on cardiovascular disorders in dialysis patients. Surg Today, 1998. 28(8): p. 811-5.

[73] Ferreira, S.R., V.A. Moises, A. Tavares, et al., Cardiovascular effects of successful renal transplantation: a 1-year sequential study of left ventricular morphology and function, and 24-hour blood pressure profile. Transplantation, 2002. 74(11): p. 1580-7.

[74] Kocak, H., K. Ceken, A. Yavuz, et al., Effect of renal transplantation on endothelial function in haemodialysis patients. Nephrol Dial Transplant, 2006. 21(1): p. 203-7.

[75] Zoungas, S., P.G. Kerr, S. Chadban, et al., Arterial function after successful renal transplantation. Kidney Int, 2004. 65(5): p. 1882-9.

[76] Chobanian, A.V., G.L. Bakris, H.R. Black, et al., The Seventh Report of the Joint National Committee on Prevention, Detection, Evaluation, and Treatment of High Blood Pressure: The JNC 7 Report 10.1001/jama.289.19.2560. JAMA, 2003: p. 289.19.2560.

[77] Standards of medical care in diabetes. Diabetes Care, 2004. 27 Suppl 1: p. S15-35.

[78] Chobanian, A.V., G.L. Bakris, H.R. Black, et al., The Seventh Report of the Joint National Committee on Prevention, Detection, Evaluation, and Treatment of High Blood Pressure: the JNC 7 report. Jama, 2003. 289(19): p. 2560-72.

[79] Lewington, S., R. Clarke, N. Qizilbash, et al., Age-specific relevance of usual blood pressure to vascular mortality: a meta-analysis of individual data for one million adults in 61 prospective studies. Lancet, 2002. 360(9349): p. 1903-13.

[80] Brantsma, A.H., S.J. Bakker, H.L. Hillege, et al., Urinary albumin excretion and its relation with C-reactive protein and the metabolic syndrome in the prediction of type 2 diabetes. Diabetes Care, 2005. 28(10): p. 2525-30. 
[81] Campbell, N.R., N.A. Khan, and S.A. Grover, Barriers and remaining questions on assessment of absolute cardiovascular risk as a starting point for interventions to reduce cardiovascular risk. J Hypertens, 2006. 24(9): p. 1683-5.

[82] Peralta, C.A., M. Kurella, J.C. Lo, et al., The metabolic syndrome and chronic kidney disease. Curr Opin Nephrol Hypertens, 2006. 15(4): p. 361-5.

[83] Yokoyama, H., M. Kuramitsu, S. Kanno, et al., Relationship between metabolic syndrome components and vascular properties in Japanese type 2 diabetic patients without cardiovascular disease or nephropathy. Diabetes Res Clin Pract, 2007. 75(2): p. 200-6.

[84] Jennett, B., Epidemiology of head injury. J Neurol Neurosurg Psychiatry, 1996. 60(4): p. 362-9.

[85] Sargent, D.J., Comparison of artificial neural networks with other statistical approaches: results from medical data sets. Cancer, 2001. 91(8 Suppl): p. 1636-42.

[86] Cross, S.S., R.F. Harrison, and R.L. Kennedy, Introduction to neural networks. Lancet, 1995. 346(8982): p. 1075-9.

[87] Goldfarb-Rumyantzev, A.S. and L. Pappas, Prediction of renal insufficiency in Pima Indians with nephropathy of type 2 diabetes mellitus. Am J Kidney Dis, 2002. 40(2): p. 252-64.

[88] West, D. and V. West, Model selection for a medical diagnostic decision support system: a breast cancer detection case. Artif Intell Med, 2000. 20(3): p. 183-204.

[89] Baxt, W.G., Application of artificial neural networks to clinical medicine. Lancet, 1995. 346(8983): p. 1135-8.

[90] Sherriff, A. and J. Ott, Artificial neural networks as statistical tools in epidemiological studies: analysis of risk factors for early infant wheeze. Paediatr Perinat Epidemiol, 2004. 18(6): p. 456-63.

[91] Schwarzer, G., W. Vach, and M. Schumacher, On the misuses of artificial neural networks for prognostic and diagnostic classification in oncology. Stat Med, 2000. 19(4): p. 541-61.

[92] Stedman's Medical Dictionary. 27th edition ed. 2000, Baltimore: Lippincott, Williams and Wilkins. p.1746.

[93] Reaven, G.M., Banting lecture 1988. Role of insulin resistance in human disease. Diabetes, 1988. 37(12): p. 1595-607.

[94] Ormezzano, O., J.P. Baguet, P. Francois, et al., Is there any real target organ damage associated with white-coat normotension? Clin Auton Res, 2004. 14(3): p. 160-6.

[95] Balkau, B. and M.A. Charles, Comment on the provisional report from the WHO consultation. European Group for the Study of Insulin Resistance (EGIR). Diabet Med, 1999. 16(5): p. 442-3.

[96] Einhorn, D., G.M. Reaven, R.H. Cobin, et al., American College of Endocrinology position statement on the insulin resistance syndrome. Endocr Pract, 2003. 9(3): p. 237-52.

[97] Grundy, S.M., H.B. Brewer, Jr., J.I. Cleeman, et al., Definition of metabolic syndrome: Report of the National Heart, Lung, and Blood Institute/American Heart Association conference on scientific issues related to definition. Circulation, 2004. 109(3): p. 433-8.

[98] Executive Summary of The Third Report of The National Cholesterol Education Program (NCEP) Expert Panel on Detection, Evaluation, And Treatment of High Blood Cholesterol In Adults (Adult Treatment Panel III). Jama, 2001. 285(19): p. 2486-97.

[99] Third Report of the National Cholesterol Education Program (NCEP) Expert Panel on Detection, Evaluation, and Treatment of High Blood Cholesterol in Adults (Adult Treatment Panel III) final report. Circulation, 2002. 106(25): p. 3143-421. 
[100] Alexander, C.M., P.B. Landsman, S.M. Teutsch, et al., NCEP-defined metabolic syndrome, diabetes, and prevalence of coronary heart disease among NHANES III participants age 50 years and older. Diabetes, 2003. 52(5): p. 1210-4.

[101] Athyros, V.G., E.S. Ganotakis, M.S. Elisaf, et al., Prevalence of vascular disease in metabolic syndrome using three proposed definitions. Int J Cardiol, 2006.

[102] Kahn, R., J. Buse, E. Ferrannini, et al., The metabolic syndrome: time for a critical appraisal: joint statement from the American Diabetes Association and the European Association for the Study of Diabetes. Diabetes Care, 2005. 28(9): p. 2289-304.

[103] Malik, S., N.D. Wong, S.S. Franklin, et al., Impact of the metabolic syndrome on mortality from coronary heart disease, cardiovascular disease, and all causes in United States adults. Circulation, 2004. 110(10): p. 1245-50.

[104] Girman, C.J., T. Rhodes, M. Mercuri, et al., The metabolic syndrome and risk of major coronary events in the Scandinavian Simvastatin Survival Study (4S) and the Air Force/Texas Coronary Atherosclerosis Prevention Study (AFCAPS/TexCAPS). Am J Cardiol, 2004. 93(2): p. 136-41.

[105] Ford, E.S., The metabolic syndrome and mortality from cardiovascular disease and all-causes: findings from the National Health and Nutrition Examination Survey II Mortality Study. Atherosclerosis, 2004. 173(2): p. 309-14.

[106] Hunt, K.J., R.G. Resendez, K. Williams, et al., National Cholesterol Education Program versus World Health Organization metabolic syndrome in relation to all-cause and cardiovascular mortality in the San Antonio Heart Study. Circulation, 2004. 110(10): p. 1251-7.

[107] Scuteri, A., S.S. Najjar, C.H. Morrell, et al., The metabolic syndrome in older individuals: prevalence and prediction of cardiovascular events: the Cardiovascular Health Study. Diabetes Care, 2005. 28(4): p. 882-7.

[108] Bakker, S.J., R.T. Gansevoort, and D. de Zeeuw, Metabolic syndrome: a fata morgana? Nephrol Dial Transplant, 2007. 22(1): p. 15-20.

[109] Blaha, M. and T.A. Elasy, Clinical use of metabolic syndrome: Why the confusion? Clinical Diabetes, 2006. 24(3): p. 125-131.

[110] Mitka, M., Metabolic syndrome recasts old cardiac, diabetes risk factors as a "new" entity. Jama, 2004. 291(17): p. 2062-3.

[111] Alberti, K.G., P. Zimmet, and J. Shaw, The metabolic syndrome--a new worldwide definition. Lancet, 2005. 366(9491): p. 1059-62.

[112] Stern, M.P., K. Williams, C. Gonzalez-Villalpando, et al., Does the metabolic syndrome improve identification of individuals at risk of type 2 diabetes and/or cardiovascular disease? Diabetes Care, 2004. 27(11): p. 2676-81.

[113] Yusuf, S., S. Hawken, S. Ounpuu, et al., Effect of potentially modifiable risk factors associated with myocardial infarction in 52 countries (the INTERHEART study): casecontrol study. Lancet, 2004. 364(9438): p. 937-52.

[114] Khoshdel, A.R., Metabolic syndrome: Erasing the problem or constructing a better answer. BMJ rapid response at www.bmj.com, 2008. 27th March 2008.

[115] Reaven, G., The metabolic syndrome or the insulin resistance syndrome? Different names, different concepts, and different goals. Endocrinol Metab Clin North Am, 2004. 33(2): p. 283-303.

[116] Robbins, D.C., L. Andersen, R. Bowsher, et al., Report of the American Diabetes Association's Task Force on standardization of the insulin assay. Diabetes, 1996. 45(2): p. 242-56. 
[117] Wallace, T.M., J.C. Levy, and D.R. Matthews, Use and abuse of HOMA modeling. Diabetes Care, 2004. 27(6): p. 1487-95.

[118] Liao, Y., S. Kwon, S. Shaughnessy, et al., Critical evaluation of adult treatment panel III criteria in identifying insulin resistance with dyslipidemia. Diabetes Care, 2004. 27(4): p. 978-83.

[119] Unger, R.H., Lipid overload and overflow: metabolic trauma and the metabolic syndrome. Trends Endocrinol Metab, 2003. 14(9): p. 398-403.

[120] Eckel, R.H., S.M. Grundy, and P.Z. Zimmet, The metabolic syndrome. Lancet, 2005. 365(9468): p. 1415-28.

[121] Bruno, G., F. Merletti, A. Biggeri, et al., Metabolic syndrome as a predictor of all-cause and cardiovascular mortality in type 2 diabetes: the Casale Monferrato Study. Diabetes Care, 2004. 27(11): p. 2689-94.

[122] Resnick, H.E., K. Jones, G. Ruotolo, et al., Insulin resistance, the metabolic syndrome, and risk of incident cardiovascular disease in nondiabetic american indians: the Strong Heart Study. Diabetes Care, 2003. 26(3): p. 861-7.

[123] Marroquin, O.C., K.E. Kip, D.E. Kelley, et al., Metabolic syndrome modifies the cardiovascular risk associated with angiographic coronary artery disease in women: a report from the Women's Ischemia Syndrome Evaluation. Circulation, 2004. 109(6): p. 714-21.

[124] Lakka, H.M., D.E. Laaksonen, T.A. Lakka, et al., The metabolic syndrome and total and cardiovascular disease mortality in middle-aged men. Jama, 2002. 288(21): p. 2709-16.

[125] Grundy, S.M., J.I. Cleeman, S.R. Daniels, et al., Diagnosis and management of the metabolic syndrome: an American Heart Association/National Heart, Lung, and Blood Institute Scientific Statement. Circulation, 2005. 112(17): p. 2735-52.

[126] Alberti, K.G. and P.Z. Zimmet, Definition, diagnosis and classification of diabetes mellitus and its complications. Part 1: diagnosis and classification of diabetes mellitus provisional report of a WHO consultation. Diabet Med, 1998. 15(7): p. 539-53.

[127] Knudsen, S.T., P.L. Poulsen, K.W. Hansen, et al., Pulse pressure and diurnal blood pressure variation: association with micro- and macrovascular complications in type 2 diabetes. Am J Hypertens, 2002. 15(3): p. 244-50.

[128] Thomas, M.C., R.J. MacIsaac, C. Tsalamandris, et al., Anemia in patients with type 1 diabetes. J Clin Endocrinol Metab, 2004. 89(9): p. 4359-63.

[129] Bongartz, L.G., M.J. Cramer, P.A. Doevendans, et al., The severe cardiorenal syndrome: 'Guyton revisited'. Eur Heart J, 2005. 26(1): p. 11-7.

[130] Becker, B., F. Kronenberg, J.T. Kielstein, et al., Renal insulin resistance syndrome, adiponectin and cardiovascular events in patients with kidney disease: the mild and moderate kidney disease study. J Am Soc Nephrol, 2005. 16(4): p. 1091-8.

[131] Yokoyama, H., M. Kuramitsu, S. Kanno, et al., Relationship between metabolic syndrome components and vascular properties in Japanese type 2 diabetic patients without cardiovascular disease or nephropathy. Diabetes Res Clin Pract, 2006.

[132] Saydah, S.H., J. Fradkin, and C.C. Cowie, Poor control of risk factors for vascular disease among adults with previously diagnosed diabetes. Jama, 2004. 291(3): p. 335-42.

[133] Fox, C.S., M.G. Larson, E.P. Leip, et al., Predictors of new-onset kidney disease in a community-based population. Jama, 2004. 291(7): p. 844-50.

[134] Amann, K., C. Wanner, and E. Ritz, Cross-Talk between the Kidney and the Cardiovascular System. J Am Soc Nephrol, 2006. 17(8): p. 2112-9.

[135] Mattu, R.K., J. Trevelyan, E.W. Needham, et al., Lipoprotein lipase gene variants relate to presence and degree of microalbuminuria in Type II diabetes. Diabetologia, 2002. 45(6): p. 905-13. 
[136] Colhoun, H.M., D.J. Betteridge, P.N. Durrington, et al., Primary prevention of cardiovascular disease with atorvastatin in type 2 diabetes in the Collaborative Atorvastatin Diabetes Study (CARDS): multicentre randomised placebo-controlled trial. Lancet, 2004. 364(9435): p. 685-96.

[137] Geluk, C.A., F.W. Asselbergs, H.L. Hillege, et al., Impact of statins in microalbuminuric subjects with the metabolic syndrome: a substudy of the PREVEND Intervention Trial. Eur Heart J, 2005. 26(13): p. 1314-20.

[138] Sola, S., M.Q. Mir, S. Lerakis, et al., Atorvastatin improves left ventricular systolic function and serum markers of inflammation in nonischemic heart failure. J Am Coll Cardiol, 2006. 47(2): p. 332-7.

[139] Elisaf, M. and D.P. Mikhailidis, Statins and renal function. Angiology, 2002. 53(5): p. 493502.

[140] Dogra, G.K., G.F. Watts, D.C. Chan, et al., Statin therapy improves brachial artery vasodilator function in patients with Type 1 diabetes and microalbuminuria. Diabet Med, 2005. 22(3): p. 239-42.

[141] Zandi-Nejad, K., V.A. Luyckx, and B.M. Brenner, Adult hypertension and kidney disease: the role of fetal programming. Hypertension, 2006. 47(3): p. 502-8.

[142] Fuenmayor, N., E. Moreira, and L.X. Cubeddu, Salt sensitivity is associated with insulin resistance in essential hypertension. Am J Hypertens, 1998. 11(4 Pt 1): p. 397-402.

[143] Sharma, A.M., U. Schorr, and A. Distler, Insulin resistance in young salt-sensitive normotensive subjects. Hypertension, 1993. 21(3): p. 273-9.

[144] Weir, M.R., Impact of salt intake on blood pressure and proteinuria in diabetes: importance of the renin-angiotensin system. Miner Electrolyte Metab, 1998. 24(6): p. 438-45.

[145] Resnick, L.M., Ionic basis of hypertension, insulin resistance, vascular disease, and related disorders. The mechanism of "syndrome X". Am J Hypertens, 1993. 6(4): p. 123S-134S.

[146] Cohn, J.N., A.A. Quyyumi, N.K. Hollenberg, et al., Surrogate markers for cardiovascular disease: functional markers. Circulation, 2004. 109(25 Suppl 1): p. IV31-46.

[147] Kimoto, E., T. Shoji, K. Shinohara, et al., Preferential stiffening of central over peripheral arteries in type 2 diabetes. Diabetes, 2003. 52(2): p. 448-52.

[148] Hopkins, K.D., E.D. Lehmann, R.L. Jones, et al., A family history of NIDDM is associated with decreased aortic distensibility in normal healthy young adult subjects. Diabetes Care, 1996. 19(5): p. 501-3.

[149] Ratto, E., G. Leoncini, F. Viazzi, et al., Ambulatory arterial stiffness index and renal abnormalities in primary hypertension. J Hypertens, 2006. 24(10): p. 2033-8.

[150] Pirro, M., G. Schillaci, G. Savarese, et al., Low-grade systemic inflammation impairs arterial stiffness in newly diagnosed hypercholesterolaemia. Eur J Clin Invest, 2004. 34(5): p. 33541.

[151] Wilkinson, I. and J.R. Cockcroft, Cholesterol, lipids and arterial stiffness. Adv Cardiol, 2007. 44: p. 261-77.

[152] Mottram, P.M., B.A. Haluska, R. Leano, et al., Relation of arterial stiffness to diastolic dysfunction in hypertensive heart disease. Heart, 2005. 91(12): p. 1551-6.

[153] Gates, P.E., H. Tanaka, J. Graves, et al., Left ventricular structure and diastolic function with human ageing. Relation to habitual exercise and arterial stiffness. Eur Heart J, 2003. 24(24): p. 2213-20.

[154] Cruickshank, K., L. Riste, S.G. Anderson, et al., Aortic Pulse-Wave Velocity and its relationship to Mortality in Diabetes and Glucose intolerance. Circulation, 2002. 106: p. 2085-90. 
[155] Laurent, S., P. Boutouyrie, R. Asmar, et al., Aortic stiffness is an independent predictor of all-cause and cardiovascular mortality in hypertensive patients. Hypertension, 2001. 37: p. 1236-41.

[156] Meaume, S., A. Rudnichi, A. Lynch, et al., Aortic pulse wave velocity as a marker of cardiovascular disease in subjects over 70 years old. J Hypertens, 2001. 19(5): p. 871-7.

[157] Cerasola, G., S. Cottone, G. Mule, et al., Microalbuminuria, renal dysfunction and cardiovascular complication in essential hypertension. J Hypertens, 1996. 14(7): p. 91520.

[158] Cruickshank, K., L. Riste, S.G. Anderson, et al., Aortic pulse-wave velocity and its relationship to mortality in diabetes and glucose intolerance: an integrated index of vascular function? Circulation, 2002. 106(16): p. 2085-90.

[159] Niskanen, L., M. Uusitupa, H. Sarlund, et al., Microalbuminuria predicts the development of serum lipoprotein abnormalities favouring atherogenesis in newly diagnosed type 2 (noninsulin-dependent) diabetic patients. Diabetologia, 1990. 33(4): p. 237-43.

[160] Smith, A., J. Karalliedde, L. De Angelis, et al., Aortic pulse wave velocity and albuminuria in patients with type 2 diabetes. J Am Soc Nephrol, 2005. 16(4): p. 1069-75.

[161] Kohara, K., Y. Tabara, R. Tachibana, et al., Microalbuminuria and arterial stiffness in a general population: the Shimanami Health Promoting Program (J-SHIPP) study. Hypertens Res, 2004. 27(7): p. 471-7.

[162] Peppa-Patrikiou, M., M. Dracopoulou, and C. Dacou-Voutetakis, Urinary endothelin in adolescents and young adults with insulin-dependent diabetes mellitus: relation to urinary albumin, blood pressure, and other factors. Metabolism, 1998. 47(11): p. 1408-12.

[163] Pedrinelli, R., G. Dell'Omo, V. Di Bello, et al., Low-grade inflammation and microalbuminuria in hypertension. Arterioscler Thromb Vasc Biol, 2004. 24(12): p. 2414-9.

[164] Aso, Y., N. Yoshida, K. Okumura, et al., Coagulation and inflammation in overt diabetic nephropathy: association with hyperhomocysteinemia. Clin Chim Acta, 2004. 348(1-2): p. 139-45.

[165] Kelbaek, H., T. Jensen, B. Feldt-Rasmussen, et al., Impaired left-ventricular function in insulin-dependent diabetic patients with increased urinary albumin excretion. Scand J Clin Lab Invest, 1991. 51(5): p. 467-73.

[166] Estacio, R.O., J.G. Regensteiner, E.E. Wolfel, et al., The association between diabetic complications and exercise capacity in NIDDM patients. Diabetes Care, 1998. 21(2): p. 291-5.

[167] Magri, P., M.A. Rao, S. Cangianiello, et al., Early impairment of renal hemodynamic reserve in patients with asymptomatic heart failure is restored by angiotensin II antagonism. Circulation, 1998. 98(25): p. 2849-54.

[168] Sarafidis, P.A. and L.M. Ruilope, Insulin resistance, hyperinsulinemia, and renal injury: mechanisms and implications. Am J Nephrol, 2006. 26(3): p. 232-44.

[169] Ruilope, L.M., D.J. van Veldhuisen, E. Ritz, et al., Renal function: the Cinderella of cardiovascular risk profile. J Am Coll Cardiol, 2001. 38(7): p. 1782-7.

[170] Safar, M.E., G.M. London, and G.E. Plante, Arterial stiffness and kidney function. Hypertension, 2004. 43(2): p. 163-8.

[171] Zoccali, C., R. Maio, G. Tripepi, et al., Inflammation as a mediator of the link between mild to moderate renal insufficiency and endothelial dysfunction in essential hypertension. J Am Soc Nephrol, 2006. 17(4 Suppl 2): p. S64-8.

[172] Levine, D.Z., Hyperfiltration, nitric oxide, and diabetic nephropathy. Curr Hypertens Rep, 2006. 8(2): p. 153-7. 
[173] Palatini, P., P. Mormino, F. Dorigatti, et al., Glomerular hyperfiltration predicts the development of microalbuminuria in stage 1 hypertension: the HARVEST. Kidney Int, 2006. 70(3): p. 578-84.

[174] Weiss, G. and L.T. Goodnough, Anemia of chronic disease. N Engl J Med, 2005. 352(10): p. 1011-23.

[175] Srivastava, P.M., M.C. Thomas, P. Calafiore, et al., Diastolic dysfunction is associated with anaemia in patients with Type II diabetes. Clin Sci (Lond), 2006. 110(1): p. 109-16.

[176] Smith, K.J., A.J. Bleyer, W.C. Little, et al., The cardiovascular effects of erythropoietin. Cardiovasc Res, 2003. 59(3): p. 538-48.

[177] Ritz, E., Managing anaemia and diabetes: a future challenge for nephrologists. Nephrol Dial Transplant, 2005. 20 Suppl 6: p. vi21-5.

[178] Kovesdy, C.P., B.K. Trivedi, K. Kalantar-Zadeh, et al., Association of anemia with outcomes in men with moderate and severe chronic kidney disease. Kidney Int, 2006. 69(3): p. 560-4.

[179] Streeter, R.P. and D. Mancini, Treatment of anemia in the patient with heart failure. Curr Treat Options Cardiovasc Med, 2005. 7(4): p. 327-32.

[180] Katzmarzyk, P.T., T.S. Church, and S.N. Blair, Cardiorespiratory fitness attenuates the effects of the metabolic syndrome on all-cause and cardiovascular disease mortality in men. Arch Intern Med, 2004. 164(10): p. 1092-7.

[181] Jouven, X., J.P. Empana, P.J. Schwartz, et al., Heart-rate profile during exercise as a predictor of sudden death. N Engl J Med, 2005. 352(19): p. 1951-8.

[182] Williams, S.G., M. Jackson, L.L. Ng, et al., Exercise duration and peak systolic blood pressure are predictive of mortality in ambulatory patients with mild-moderate chronic heart failure. Cardiology, 2005. 104(4): p. 221-6.

[183] Bonapace, S., A. Rossi, M. Cicoira, et al., Aortic distensibility independently affects exercise tolerance in patients with dilated cardiomyopathy. Circulation, 2003. 107(12): p. 1603-8.

[184] Boyer, J.K., S. Thanigaraj, K.B. Schechtman, et al., Prevalence of ventricular diastolic dysfunction in asymptomatic, normotensive patients with diabetes mellitus. Am J Cardiol, 2004. 93(7): p. 870-5.

[185] Vinereanu, D., E. Nicolaides, A.C. Tweddel, et al., Subclinical left ventricular dysfunction in asymptomatic patients with Type II diabetes mellitus, related to serum lipids and glycated haemoglobin. Clin Sci (Lond), 2003. 105(5): p. 591-9.

[186] McMahon, A.C., R.U. Naqvi, M.J. Hurst, et al., Diastolic dysfunction and abnormality of the $\mathrm{Na}+/ \mathrm{Ca}+$ exchanger in single uremic cardiac myocytes. Kidney Int, 2006. 69(5): p. 846-51.

[187] Ando, K. and T. Fujita, Anti-diabetic effect of blockade of the renin-angiotensin system. Diabetes Obes Metab, 2006. 8(4): p. 396-403.

[188] Derosa, G., A.F. Cicero, A. Dangelo, et al., Thiazolidinedione effects on blood pressure in diabetic patients with metabolic syndrome treated with glimepiride. Hypertens Res, 2005. 28(11): p. 917-24.

[189] Raji, A. and J. Plutzky, Insulin resistance, diabetes, and atherosclerosis: thiazolidinediones as therapeutic interventions. Curr Cardiol Rep, 2002. 4(6): p. 514-21.

[190] Undas, A., K.E. Brummel-Ziedins, and K.G. Mann, Statins and blood coagulation. Arterioscler Thromb Vasc Biol, 2005. 25(2): p. 287-94.

[191] Fliser, D., K. Buchholz, and H. Haller, Antiinflammatory effects of angiotensin II subtype 1 receptor blockade in hypertensive patients with microinflammation. Circulation, 2004. 110(9): p. 1103-7. 
[192] Gross, M.L., K. Amann, and E. Ritz, Nephron number and renal risk in hypertension and diabetes. J Am Soc Nephrol, 2005. 16 Suppl 1: p. S27-9.

[193] Hobson, A., P.A. Kalra, and P.R. Kalra, Cardiology and nephrology: time for a more integrated approach to patient care? Eur Heart J, 2005. 26(16): p. 1576-8.

[194] Lee, Y.J. and J.C. Tsai, ACE gene insertion/deletion polymorphism associated with 1998 World Health Organization definition of metabolic syndrome in Chinese type 2 diabetic patients. Diabetes Care, 2002. 25(6): p. 1002-8.

[195] Zozulinska, D. and B. Wierusz-Wysocka, Type 2 diabetes mellitus as inflammatory disease. Diabetes Res Clin Pract, 2006.

[196] Li, J.J., C.H. Fang, and R.T. Hui, Is hypertension an inflammatory disease? Med Hypotheses, 2005. 64(2): p. 236-40.

[197] Li, J.J. and J.L. Chen, Inflammation may be a bridge connecting hypertension and atherosclerosis. Med Hypotheses, 2005. 64(5): p. 925-9.

[198] Lind, L., Circulating markers of inflammation and atherosclerosis. Atherosclerosis, 2003. 169(2): p. 203-214.

[199] Shoelson, S.E., J. Lee, and A.B. Goldfine, Inflammation and insulin resistance. J Clin Invest, 2006. 116(7): p. 1793-801.

[200] Ridker, P.M., N. Rifai, N.R. Cook, et al., Non-HDL cholesterol, apolipoproteins A-I and B100, standard lipid measures, lipid ratios, and CRP as risk factors for cardiovascular disease in women. Jama, 2005. 294(3): p. 326-33.

[201] Sagastagoitia, J.D., Y. Saez, M. Vacas, et al., Association between inflammation, lipid and hemostatic factors in patients with stable angina. Thromb Res, 2006.

[202] Stuveling, E.M., S.J. Bakker, H.L. Hillege, et al., C-reactive protein modifies the relationship between blood pressure and microalbuminuria. Hypertension, 2004. 43(4): p. 791-6.

[203] Ridker, P.M., P.W. Wilson, and S.M. Grundy, Should C-reactive protein be added to metabolic syndrome and to assessment of global cardiovascular risk? Circulation, 2004. 109(23): p. 2818-25.

[204] Stehouwer, C.D., M.A. Gall, J.W. Twisk, et al., Increased urinary albumin excretion, endothelial dysfunction, and chronic low-grade inflammation in type 2 diabetes: progressive, interrelated, and independently associated with risk of death. Diabetes, 2002. 51(4): p. 1157-65.

[205] Palmieri, V., R.P. Tracy, M.J. Roman, et al., Relation of left ventricular hypertrophy to inflammation and albuminuria in adults with type 2 diabetes: the strong heart study. Diabetes Care, 2003. 26(10): p. 2764-9.

[206] Devaraj, S., R.S. Rosenson, and I. Jialal, Metabolic syndrome: an appraisal of the proinflammatory and procoagulant status. Endocrinol Metab Clin North Am, 2004. 33(2): p. 431-53, table of contents.

[207] Matteucci, E., J. Rosada, M. Pinelli, et al., Systolic blood pressure response to exercise in type 1 diabetes families compared with healthy control individuals. J Hypertens, 2006. 24(9): p. 1745-51.

[208] Keung, Y.K. and J. Owen, Iron deficiency and thrombosis: literature review. Clin Appl Thromb Hemost, 2004. 10(4): p. 387-91.

[209] Nieuwdorp, M., E.S. Stroes, J.C. Meijers, et al., Hypercoagulability in the metabolic syndrome. Curr Opin Pharmacol, 2005. 5(2): p. 155-9.

[210] Sechi, L.A., L. Zingaro, C. Catena, et al., Relationship of fibrinogen levels and hemostatic abnormalities with organ damage in hypertension. Hypertension, 2000. 36(6): p. 978-85. 
[211] Danesh, J., S. Lewington, S.G. Thompson, et al., Plasma fibrinogen level and the risk of major cardiovascular diseases and nonvascular mortality: an individual participant metaanalysis. Jama, 2005. 294(14): p. 1799-809.

[212] Marcucci, R., A.M. Gori, F. Giannotti, et al., Markers of hypercoagulability and inflammation predict mortality in patients with heart failure. J Thromb Haemost, 2006. 4(5): p. 1017-22.

[213] Vicari, A.M., M.V. Taglietti, F. Pellegatta, et al., Deranged platelet calcium homeostasis in diabetic patients with end-stage renal failure. A possible link to increased cardiovascular mortality? Diabetes Care, 1996. 19(10): p. 1062-6.

[214] Haffner, S.M., L. Mykkanen, A. Festa, et al., Insulin-resistant prediabetic subjects have more atherogenic risk factors than insulin-sensitive prediabetic subjects: implications for preventing coronary heart disease during the prediabetic state. Circulation, 2000. 101(9): p. 975-80.

[215] Isomaa, B., P. Almgren, T. Tuomi, et al., Cardiovascular morbidity and mortality associated with the metabolic syndrome. Diabetes Care, 2001. 24(4): p. 683-9.

[216] Bloomgarden, Z.T., Third Annual World Congress on the Insulin Resistance Syndrome: Atherothrombotic disease. Diabetes Care, 2006. 29(8): p. 1973-80.

[217] Juhan-Vague, I., M.C. Alessi, A. Mavri, et al., Plasminogen activator inhibitor-1, inflammation, obesity, insulin resistance and vascular risk. J Thromb Haemost, 2003. 1(7): p. 1575-9.

[218] Inomat, S., M. Haneda, T. Moriya, et al., [Revised criteria for the early diagnosis of diabetic nephropathy]. Nippon Jinzo Gakkai Shi, 2005. 47(7): p. 767-9.

[219] Deferrari, G., M. Ravera, and V. Berruti, Treatment of diabetic nephropathy in its early stages. Diabetes Metab Res Rev, 2003. 19(2): p. 101-14.

[220] Ferrier, K.E., M.H. Muhlmann, J.P. Baguest, et al., Intensive Cholesterol Reduction lowers blood pressure and large artery stiffness in isolated systolic hypertension. Journal of American College of Cardiology, 2002. 39(6): p. 1020-5.

[221] Maiese, K., F. Li, and Z.Z. Chong, New avenues of exploration for erythropoietin. Jama, 2005. 293(1): p. 90-5.

[222] Khoshdel, A., S. Carney, A. Gillies, et al., Potential roles of erythropoietin in the management of anaemia and other complications diabetes. Diabetes Obes Metab, 2007.

[223] Levey, A.S., J. Coresh, E. Balk, et al., National Kidney Foundation practice guidelines for chronic kidney disease: evaluation, classification, and stratification. Ann Intern Med, 2003. 139(2): p. 137-47.

[224] Fox, K.M., Efficacy of perindopril in reduction of cardiovascular events among patients with stable coronary artery disease: randomised, double-blind, placebo-controlled, multicentre trial (the EUROPA study). Lancet, 2003. 362(9386): p. 782-8.

[225] Randomised trial of a perindopril-based blood-pressure-lowering regimen among 6,105 individuals with previous stroke or transient ischaemic attack. Lancet, 2001. 358(9287): p. 1033-41.

[226] Yusuf, S., P. Sleight, J. Pogue, et al., Effects of an angiotensin-converting-enzyme inhibitor, ramipril, on cardiovascular events in high-risk patients. The Heart Outcomes Prevention Evaluation Study Investigators. N Engl J Med, 2000. 342(3): p. 145-53.

[227] Bianchi, S., R. Bigazzi, and V.M. Campese, Long-term effects of spironolactone on proteinuria and kidney function in patients with chronic kidney disease. Kidney Int, 2006. 70(12): p. 2116-23.

[228] Casas, J.P., W. Chua, S. Loukogeorgakis, et al., Effect of inhibitors of the renin-angiotensin system and other antihypertensive drugs on renal outcomes: systematic review and metaanalysis. Lancet, 2005. 366(9502): p. 2026-33. 
[229] Jafar, T.H., P.C. Stark, C.H. Schmid, et al., Progression of chronic kidney disease: the role of blood pressure control, proteinuria, and angiotensin-converting enzyme inhibition: a patient-level meta-analysis. Ann Intern Med, 2003. 139(4): p. 244-52.

[230] Jafar, T.H., C.H. Schmid, M. Landa, et al., Angiotensin-converting enzyme inhibitors and progression of nondiabetic renal disease. A meta-analysis of patient-level data. Ann Intern Med, 2001. 135(2): p. 73-87.

[231] Mann, J.F., W.M. McClellan, R. Kunz, et al., Progression of renal disease--can we forget about inhibition of the renin-angiotensin system? Nephrol Dial Transplant, 2006. 21(9): p. 2348-51; discussion 2352-3.

[232] Bilous, R.W., Treatment strategies for early nephropathy, in Issues in nephrology. accessed 2004, www.medscape.com.

[233] Palatini, P., A. Benetos, G. Grassi, et al., Identification and management of the hypertensive patient with elevated heart rate: statement of a European Society of Hypertension Consensus Meeting. J Hypertens, 2006. 24(4): p. 603-10.

[234] Bakris, G.L., P. Hart, and E. Ritz, Beta blockers in the management of chronic kidney disease. Kidney Int, 2006. 70(11): p. 1905-13.

[235] Khoshdel, A., S. Carney, A. Gillies, et al., Potential roles of erythropoietin in the management of anaemia and other complications diabetes. Diabetes Obes Metab, 2008. 10(1): p. 1-9.

[236] Gross, J.L., M.J. de Azevedo, S.P. Silveiro, et al., Diabetic nephropathy: diagnosis, prevention, and treatment. Diabetes Care, 2005. 28(1): p. 164-76.

[237] Bloomgarden, Z.T., Diabetic nephropathy. Diabetes Care, 2005. 28(3): p. 745-51.

[238] McGowan, T.A., Y. Zhu, and K. Sharma, Transforming growth factor-beta: a clinical target for the treatment of diabetic nephropathy. Curr Diab Rep, 2004. 4(6): p. 447-54.

[239] Mangoni, A.A., R.A. Sherwood, B. Asonganyi, et al., Short-term oral folic acid supplementation enhances endothelial function in patients with type 2 diabetes. Am J Hypertens, 2005. 18(2 Pt 1): p. 220-6.

[240] Samuel, C.S. and T.D. Hewitson, Relaxin in cardiovascular and renal disease. Kidney Int, 2006. 69(9): p. 1498-502.

[241] Ashton, N., Renal and vascular actions of urotensin II. Kidney Int, 2006. 70(4): p. 624-9.

[242] Varghese, Z., J.F. Moorhead, and X.Z. Ruan, The PPARalpha ligand fenofibrate: meeting multiple targets in diabetic nephropathy. Kidney Int, 2006. 69(9): p. 1490-1.

[243] Vitale, C., G. Mercuro, A. Cornoldi, et al., Metformin improves endothelial function in patients with metabolic syndrome. J Intern Med, 2005. 258(3): p. 250-6.

[244] Lipton, S.A., Erythropoietin for neurologic protection and diabetic neuropathy. N Engl J Med, 2004. 350(24): p. 2516-7.

[245] Gomez-Garre, D., J.L. Martin-Ventura, R. Granados, et al., Losartan improves resistance artery lesions and prevents CTGF and TGF-beta production in mild hypertensive patients. Kidney Int, 2006. 69(7): p. 1237-44.

[246] Oliver, J.J. and D.E. Newby, Endothelial fibrinolytic function in hypertension: the expanding story. J Hypertens, 2005. 23(8): p. 1471-2.

[247] Roldan, V. and F. Marin, Are we content with lowering blood pressure alone, or should we be asking something more from the antihypertensive drugs we use?: effects of antihypertensive agents on fibrinolytic function. J Hum Hypertens, 2004. 18(10): p. 681-3.

[248] Ritz, E., PPARgamma agonists: killing two birds with one stone? J Hypertens, 2004. 22(9): p. 1673-4.

[249] Park, C.W., Y. Zhang, X. Zhang, et al., PPARalpha agonist fenofibrate improves diabetic nephropathy in db/db mice. Kidney Int, 2006. 69(9): p. 1511-7. 


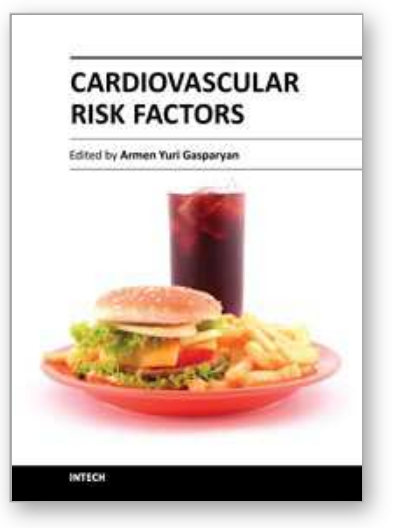

\author{
Cardiovascular Risk Factors \\ Edited by Prof. Armen Gasparyan
}

ISBN 978-953-51-0240-3

Hard cover, 498 pages

Publisher InTech

Published online 14, March, 2012

Published in print edition March, 2012

Cardiovascular risk factors contribute to the development of cardiovascular disease from early life. It is thus crucial to implement preventive strategies addressing the burden of cardiovascular disease as early as possible. A multidisciplinary approach to the risk estimation and prevention of vascular events should be adopted at each level of health care, starting from the setting of perinatology. Recent decades have been marked with major advances in this field, with the emergence of a variety of new inflammatory and immunemediated markers of heightened cardiovascular risk in particular. The current book reflects some of the emerging concepts in cardiovascular pathophysiology and the shifting paradigm of cardiovascular risk estimation. It comprehensively covers primary and secondary preventive measures targeted at different age and gender groups. Attention is paid to inflammatory and metabolic markers of vascular damage and to the assessment of vascular function by noninvasive standardized ultrasound techniques. This is a must-read book for all health professionals and researchers tackling the issue of cardiovascular burden at individual and community level. It can also serve as a didactic source for postgraduate medical students.

\title{
How to reference
}

In order to correctly reference this scholarly work, feel free to copy and paste the following:

Ali Reza Khoshdel (2012). Cardiovascular Risk Assessment in Diabetes and Chronic Kidney Diseases: A New Insight and Emerging Strategies, Cardiovascular Risk Factors, Prof. Armen Gasparyan (Ed.), ISBN: 978-95351-0240-3, InTech, Available from: http://www.intechopen.com/books/cardiovascular-riskfactors/cardiovascular-risk-assessment-in-diabetes-and-chronic-kidney-disease-a-new-insight-and-emergingstr

\section{INTECH}

open science | open minds

\section{InTech Europe}

University Campus STeP Ri

Slavka Krautzeka 83/A

51000 Rijeka, Croatia

Phone: +385 (51) 770447

Fax: +385 (51) 686166

www.intechopen.com

\section{InTech China}

Unit 405, Office Block, Hotel Equatorial Shanghai

No.65, Yan An Road (West), Shanghai, 200040, China

中国上海市延安西路65号上海国际贵都大饭店办公楼405单元

Phone: +86-21-62489820

Fax: +86-21-62489821 
(C) 2012 The Author(s). Licensee IntechOpen. This is an open access article distributed under the terms of the Creative Commons Attribution 3.0 License, which permits unrestricted use, distribution, and reproduction in any medium, provided the original work is properly cited. 